Supporting Information for

\title{
Rapid Generation of Block Copolymer Libraries using Automated Chromatographic Separation
}

Cheng Zhang, ${ }^{\dagger, \mathrm{F}, l}$ Morgan W. Bates, ${ }^{\dagger}$ Zhishuai Geng, ${ }^{\dagger}$ Adam E. Levi, ${ }^{\dagger} \%$ Daniel Vigil, ${ }^{\dagger}$ Stephanie M. Barbon, ${ }^{\dagger}$ Tessa Loman, ${ }^{\dagger}$ Kris T. Delaney, ${ }^{\dagger}$ Glenn H. Fredrickson, ${ }^{\dagger,+,{ }^{\dagger}}$ Christopher M. Bates, $* \sharp, \S, \%$ Andrew K. Whittaker*,F,l and Craig J. Hawker*,†, ${ }^{*}, \%$

${ }^{\dagger}$ Materials Research Laboratory, ${ }^{\dagger}$ Department of Materials, and ${ }^{\S}$ Department of Chemical Engineering, ${ }^{\%}$ Department of Chemistry and Biochemistry, University of California, Santa Barbara, California 93106, United States

${ }^{\mathrm{F}}$ Australian Institute for Bioengineering and Nanotechnology, "ARC Centre of Excellence in Convergent Bio-Nano Science and Technology, University of Queensland, Brisbane, Queensland 4072, Australia 


\section{Materials}

All reagents were purchased from Sigma Aldrich and used as received except where noted. Tris[2-(dimethylamino)ethyl]amine ( $\mathrm{Me}_{6}$ Tren) was obtained from Alfa Aesar. Dodecyl acrylate (DDA, > 98\%) was obtained from TCI chemicals and trifluoroethyl acrylate (TFEA) was purchased from Matrix Scientific. Monomers were passed through a column of basic alumina to remove inhibitor prior to use. Tin(II) 2-ethylhexanoate $\left(\operatorname{Sn}(\mathrm{Oct})_{2}\right)$ was fractionally distilled $3 \times$ under reduced pressure $\left(50 \mathrm{mtorr}, 150{ }^{\circ} \mathrm{C}\right)$ and stored in a nitrogen filled glovebox before use. ( \pm )-Lactide was obtained from Corbion and recrystallized once from ethyl acetate and from toluene. Monocarbinol terminated polydimethylsiloxane (PDMS, $1 \mathrm{kDa}$ ) was obtained from Gelest.

\section{Molecular Characterization}

${ }^{1} \mathrm{H}$ nuclear magnetic resonance (NMR) spectra were recorded on a Varian VNMRS $600 \mathrm{MHz}$ spectrometer. Chemical shifts $(\delta)$ are reported in ppm relative to the residual $\mathrm{CHCl}_{3}(7.26 \mathrm{ppm})$. Size exclusion chromatography (SEC) was conducted on a Waters e2695 ambient separation module equipped with a Waters 2414 differential refractive index detector using tetrahydrofuran as the eluent at a flow rate of $1 \mathrm{~mL} / \mathrm{min}$. Number-average molar mass $\left(M_{\mathrm{n}}\right)$ and weight-average molar mass $\left(M_{\mathrm{W}}\right)$ were determined relative to linear polystyrene standards and used to estimate the molar mass dispersity $\left(Ð=M_{\mathrm{w}} / M_{\mathrm{n}}\right)$. Matrix-assisted laser desorption ionization time-of-flight (MALDI-ToF) mass spectrometry was conducted using a Bruker Microflex LRF MALDI-ToF mass spectrometer, equipped with a $60 \mathrm{~Hz}$ nitrogen laser at 337 nm. 2,5-Dihydroxybenzoic acid (DHB)/sodium trifluoroacetate (NaTFA) or trans-2-[3-(4-tertbutylphenyl)-2-methyl-2propenylidene]malononitrile (DCTB)/Na-TFA was used as the matrix. Homopolymer densities were determined at room temperature using a MicroMeritics AccuPyc 1340 Pycnometer based on the gas displacement technique (helium).

Automatic flash chromatography was performed on a Biotage Isolera unit installed with an evaporative light scattering detector (ELSD), using Biotage KP-SIL SNAP cartridge series $(100 \mathrm{~g} / 340 \mathrm{~g})$ eluted with suitable solvent pairs. All chromatographic solvents were ACS grade or better and used without further purification. In fractionation experiments, the mass recovery was taken as the ratio of the collected mass to the injected mass.

SAXS measurements of bulk samples were conducted using a custom-built SAXS diffractometer at the Materials Research Laboratory (MRL) X-ray facility (University of California, Santa Barbara). For these experiments, $1.54 \AA \mathrm{Cu} \mathrm{K \alpha} \mathrm{X}$-rays were generated using a Genix $50 \mathrm{~W}$ X-ray microsource ( $50 \mu \mathrm{m}$ micro-focus) equipped with FOX2D collimating multilayer optics (Xenocs, France) and high efficiency scatterless single crystal/metal hybrid slits. SAXS data were also acquired at beamline 1-5 of the Stanford Synchrotron Radiation Lightsource (SSRL). The beamline was configured with an X-ray wavelength of $\lambda=1.00462$ $\AA$, sample-to-detector distance of $2974 \mathrm{~mm}$ and focused to a spot size of $300 \mu \mathrm{m} \times 300 \mu \mathrm{m}$. Two-dimensional scattering patterns were collected on a Rayonix 165 CCD Camera. Samples were mounted on washers for SAXS experiments. 


\section{Synthesis and fractionation of PDDA- $b$-PLA diblock copolymer}

Synthetic details can be found in a previous report. ${ }^{1}$

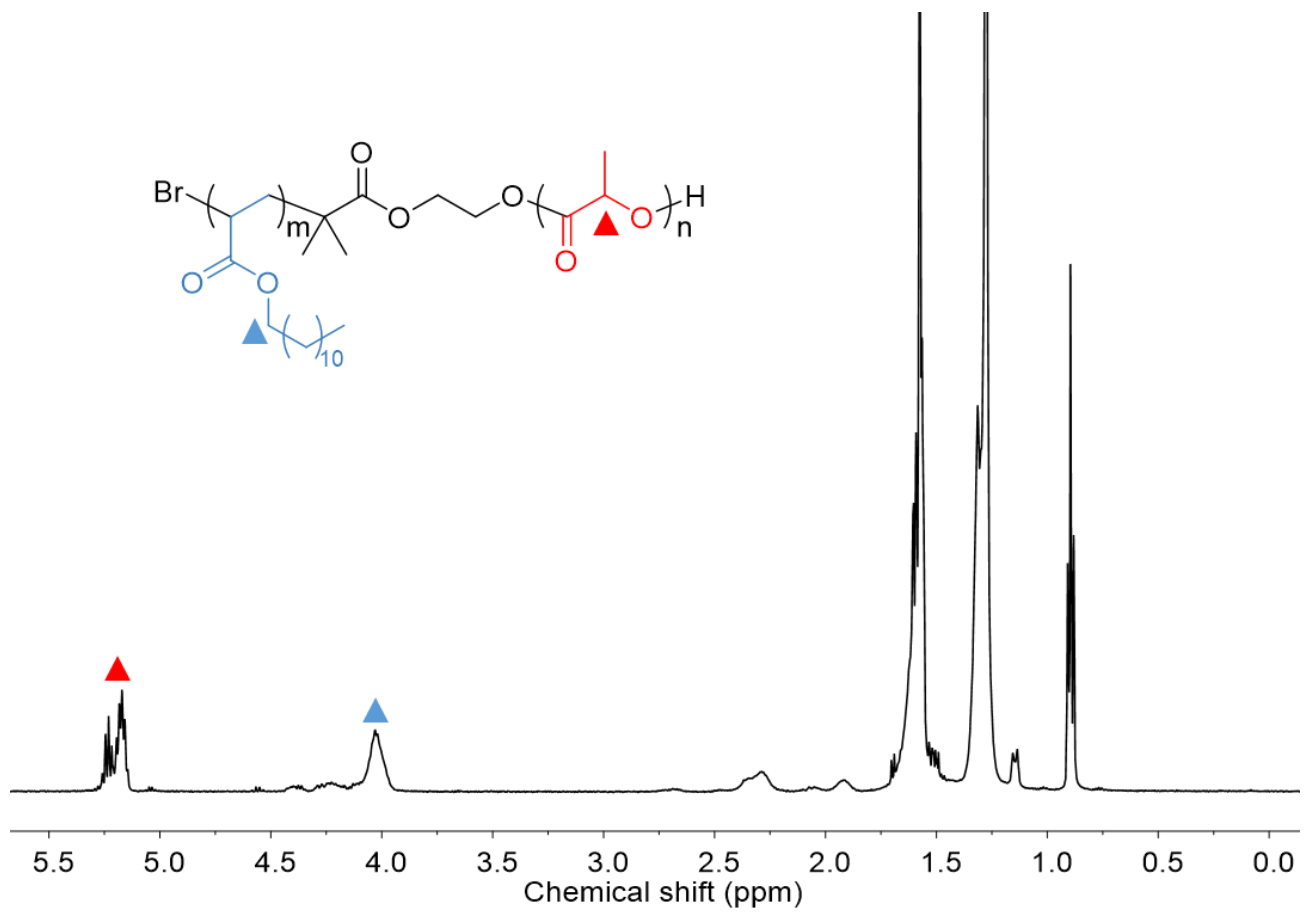

Figure S1. ${ }^{1} \mathrm{H}$ NMR spectrum of a PDDA- $b$-PLA diblock copolymer with characteristic resonances used to calculate the average composition indicated by triangles.

Table S1. Molecular characterization data for PDDA- $b$-PLA diblock copolymer.

\begin{tabular}{cccccccccc}
\hline$D P_{\mathrm{PDDA}^{\mathrm{a}}}$ & $D P_{\mathrm{PLA}^{\mathrm{a}}}$ & $\begin{array}{c}M_{\mathrm{n}, \mathrm{PDDA}} \\
(\mathrm{g} / \mathrm{mol})^{\mathrm{a}}\end{array}$ & $\begin{array}{c}M_{\mathrm{n}, \mathrm{PLA}} \\
(\mathrm{g} / \mathrm{mol})^{\mathrm{a}}\end{array}$ & $\begin{array}{c}M_{\mathrm{n}, \mathrm{BCP}} \\
(\mathrm{g} / \mathrm{mol})^{\mathrm{a}}\end{array}$ & $D^{\mathrm{b}}$ & $f_{\mathrm{PLA}^{\mathrm{c}}}$ & $N^{\mathrm{d}}$ & $\begin{array}{c}T_{\mathrm{ODT}} \\
\left({ }^{\circ} \mathrm{C}\right)^{\mathrm{e}}\end{array}$ & Phase $^{f}$ \\
\hline 10 & 22 & 2400 & 1600 & 4000 & 1.08 & 0.34 & 54 & 87 & HEX \\
\hline
\end{tabular}

${ }^{a}$ Degree of polymerization (DP) and number-average molar mass of each block determined from ${ }^{1} \mathrm{H}$ NMR end-group analysis. ${ }^{b}$ Dispersity in molar mass determined by SEC using conventional calibration in chloroform relative to PS standards. ${ }^{c}$ Average volume fraction of PLA based on reported homopolymer densities at $140{ }^{\circ} \mathrm{C}\left(0.94\right.$ and $1.24 \mathrm{~g} / \mathrm{cm}^{3}$ for PDDA and PLA, respectively ${ }^{1}$ ) and ${ }^{1} \mathrm{H}$ NMR. ${ }^{d}$ Volumetric degree of polymerization based on reported homopolymer densities and the reference volume, $v_{0}=118 \AA^{3}$. ${ }^{e}$ Order-disorder transition temperature determined from oscillatory rheology measurements $(\omega=1 \mathrm{rad} / \mathrm{s}, \gamma=0.5 \%)$ performed on heating at a rate of $1{ }^{\circ} \mathrm{C} / \mathrm{min}$ as previously reported. ${ }^{2}{ }^{f}$ Determined by SAXS at temperatures below the $T_{\mathrm{ODT}}$. 


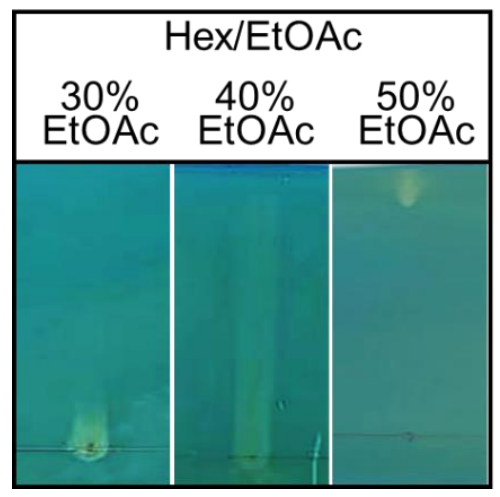

Figure S2. Thin-layer chromatography (TLC) analysis of the parent PDDA- $b$-PLA, stained with bromocresol green. Streaking indicates an eluent condition amenable to compositional fractionation.

Table S2. Gradient profile for PDDA-b-PLA separation (eluent: hexane/ethyl acetate).

\begin{tabular}{ccc}
\hline \%EtOAc (start) & \%EtOAc (end) & Column Volume (CV) \\
\hline 0 & 0 & 1 \\
0 & 42 & 4 \\
42 & 42 & 5 \\
\hline
\end{tabular}
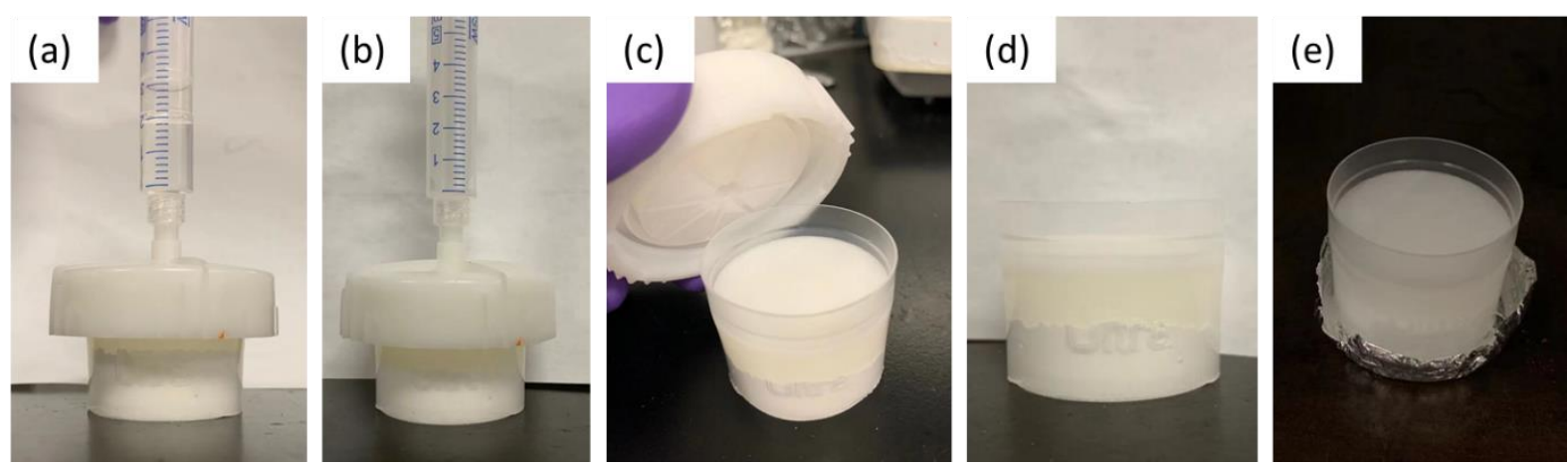

Figure S3. Procedures for loading the parent block copolymer sample onto a samplet. (a-b) The parent block copolymer was dissolved in good organic solvent and loaded onto the samplet using a syringe. (c-d) The screw-top cap was then removed. (e) The samplet was dried under vacuum at $60{ }^{\circ} \mathrm{C}$ overnight. 


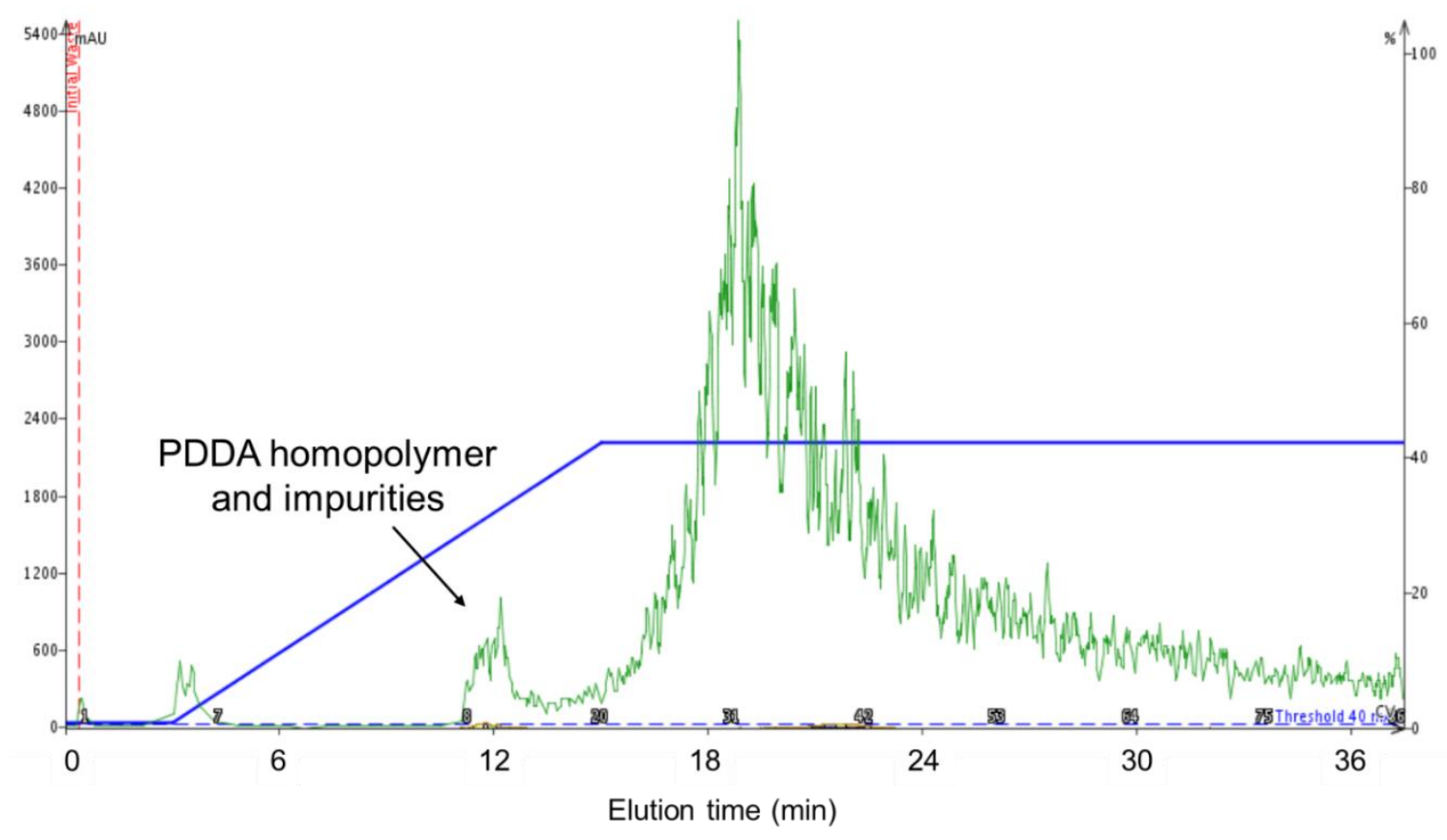

Figure S4. Representative ELSD signal for the separation of PDDA- $b$-PLA diblock copolymer.<smiles>COC(=O)C(C)(C)C(=O)OCCOC(=O)C(C)(C)C(=O)OC</smiles>

b $x_{10}$

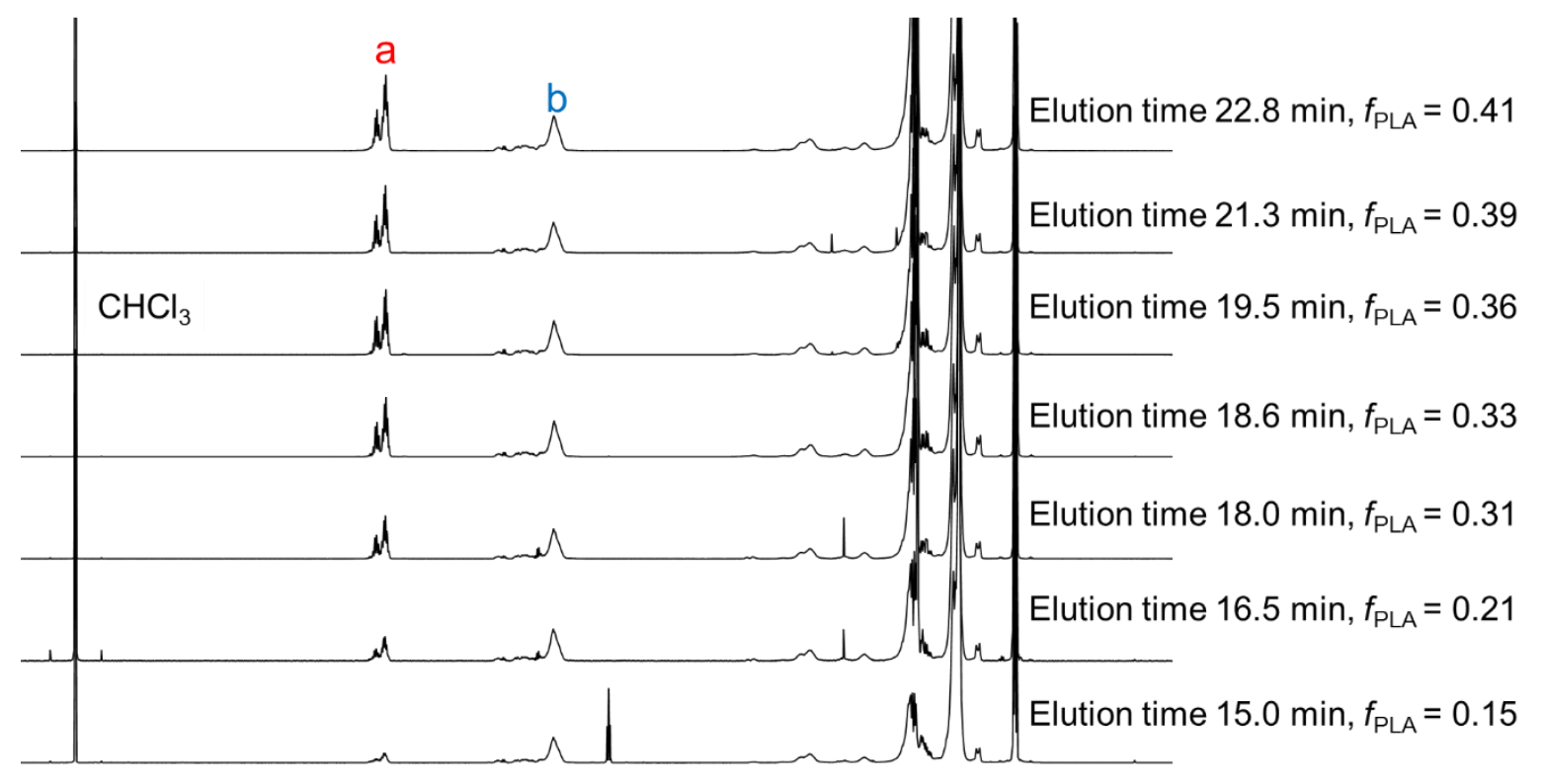

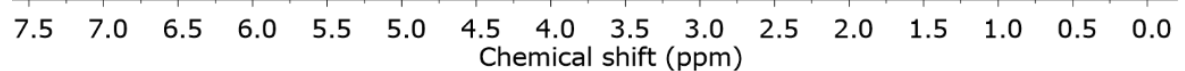

Figure S5. ${ }^{1} \mathrm{H}$ NMR spectra of fractionated PDDA- $b$-PLA diblock copolymers. The integration ratio $\mathrm{a} / \mathrm{b}$ increases with each fraction corresponding to a larger $f_{\text {PLA }}$ with increasing elution time. 


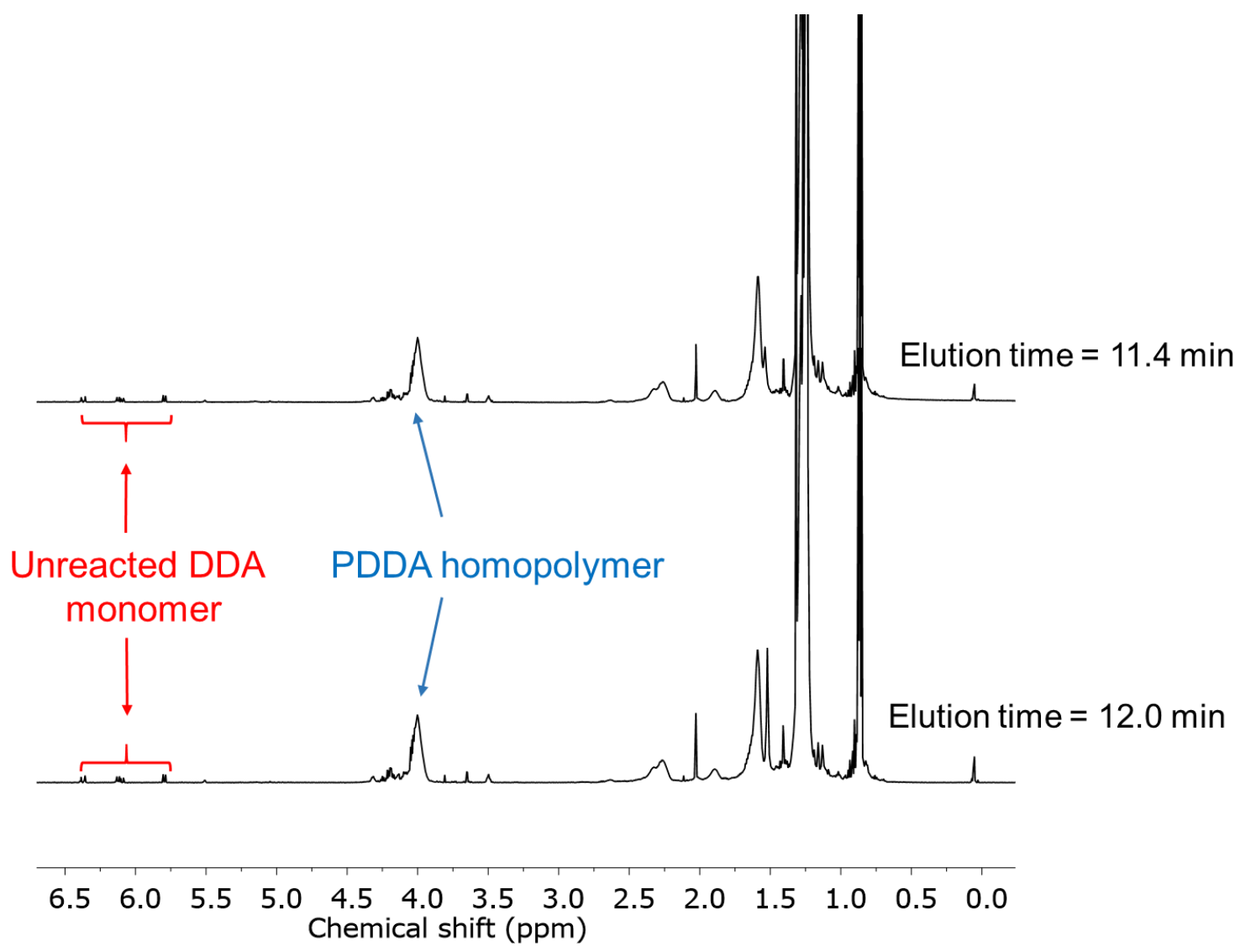

Figure S6. ${ }^{1} \mathrm{H}$ NMR spectra of fractionated PDDA- $b$-PLA diblock copolymers obtained at early elution times $(11.4$ and $12.0 \mathrm{~min})$ indicate the presence of PDDA homopolymer $(\approx 4.0$ $\mathrm{ppm}$ ) in the parent PDDA- $b$-PLA. The absence of resonances at $\approx 5.2$ and $1.5 \mathrm{ppm}$ implies that no PLA segment is presented at early elution times. The chromatographic fractionation technique efficiently removes this homopolymer. 


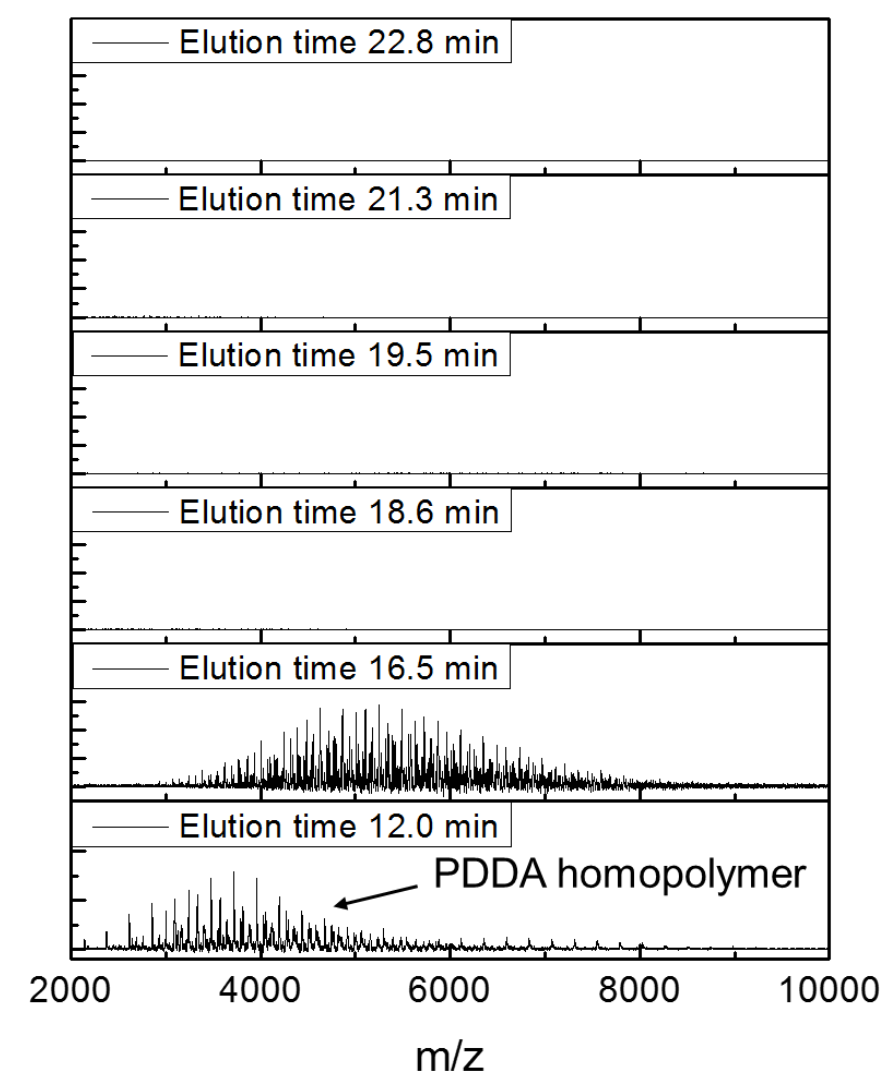

Figure S7. MALDI analysis of fractionated PDDA- $b$-PLA. The BCP that eluted at $12.0 \mathrm{~min}$ contains PDDA homopolymer (see also Figure S6). No homopolymer is evident from the MALDI spectrum at elution times $\geq 16.5 \mathrm{~min}$. We attribute the lack of a MALDI signal at elution times of 18.6-22.8 min to insufficient ionization due to high molecular weight; ${ }^{1} \mathrm{H}$ NMR (Figure S5) confirms these samples do indeed contain block copolymer. 
Table S3. Molecular characterization data for fractionated PDDA- $b$-PLA BCPs.

\begin{tabular}{ccccccc}
\hline $\begin{array}{c}\text { Elution time } \\
(\mathrm{min})\end{array}$ & $\begin{array}{c}M_{\mathrm{n}, \text { PDDA }} \\
(\mathrm{g} / \mathrm{mol})\end{array}$ & $\begin{array}{c}M_{\mathrm{n}, \mathrm{PLA}} \\
(\mathrm{g} / \mathrm{mol})\end{array}$ & $\begin{array}{c}M_{\mathrm{n}, \mathrm{BCP}} \\
(\mathrm{g} / \mathrm{mol})\end{array}$ & $Ð$ & $f_{\text {PLA }}$ & $\begin{array}{c}\text { Mass } \\
(\mathrm{mg})\end{array}$ \\
\hline 15.0 & 2400 & 500 & 2900 & 1.079 & 0.146 & 5.2 \\
15.9 & 2640 & 720 & 3360 & 1.074 & - & 9.3 \\
16.5 & 2880 & 940 & 3820 & 1.072 & 0.210 & 25.6 \\
17.1 & 2760 & 1120 & 3880 & 1.068 & 0.248 & 64.1 \\
17.7 & 2760 & 1370 & 4130 & 1.066 & 0.288 & 117.7 \\
18.0 & 2640 & 1440 & 4080 & 1.065 & 0.308 & 135.9 \\
18.3 & 2520 & 1500 & 4030 & 1.064 & 0.329 & 124.2 \\
18.6 & 2640 & 1580 & 4200 & 1.063 & 0.329 & 114.1 \\
18.9 & 2580 & 1660 & 4240 & 1.061 & 0.344 & 98.8 \\
19.5 & 2330 & 1580 & 3900 & 1.060 & 0.357 & 81.6 \\
20.1 & 2500 & 1800 & 4300 & 1.060 & 0.370 & 65.3 \\
20.7 & 2400 & 1800 & 4200 & 1.059 & 0.380 & 46.9 \\
21.3 & 2450 & 1900 & 4360 & 1.058 & 0.390 & 46.2 \\
22.2 & 2400 & 1940 & 4340 & 1.058 & 0.398 & 32.7 \\
22.8 & 2220 & 1870 & 4100 & 1.058 & 0.408 & 24.3 \\
24.3 & 2160 & 1900 & 4070 & 1.057 & 0.419 & 18.6 \\
25.8 & 2250 & 2000 & 4250 & 1.056 & 0.433 & 16.5 \\
28.2 & 2200 & 2130 & 4330 & 1.055 & 0.442 & 14.1 \\
29.7 & 2400 & 2320 & 4720 & 1.054 & 0.441 & 14.9 \\
31.8 & 2230 & 2280 & 4510 & 1.055 & 0.454 & 10.1 \\
34.5 & 2000 & 2140 & 4140 & 1.055 & 0.466 & 5.6 \\
\hline
\end{tabular}
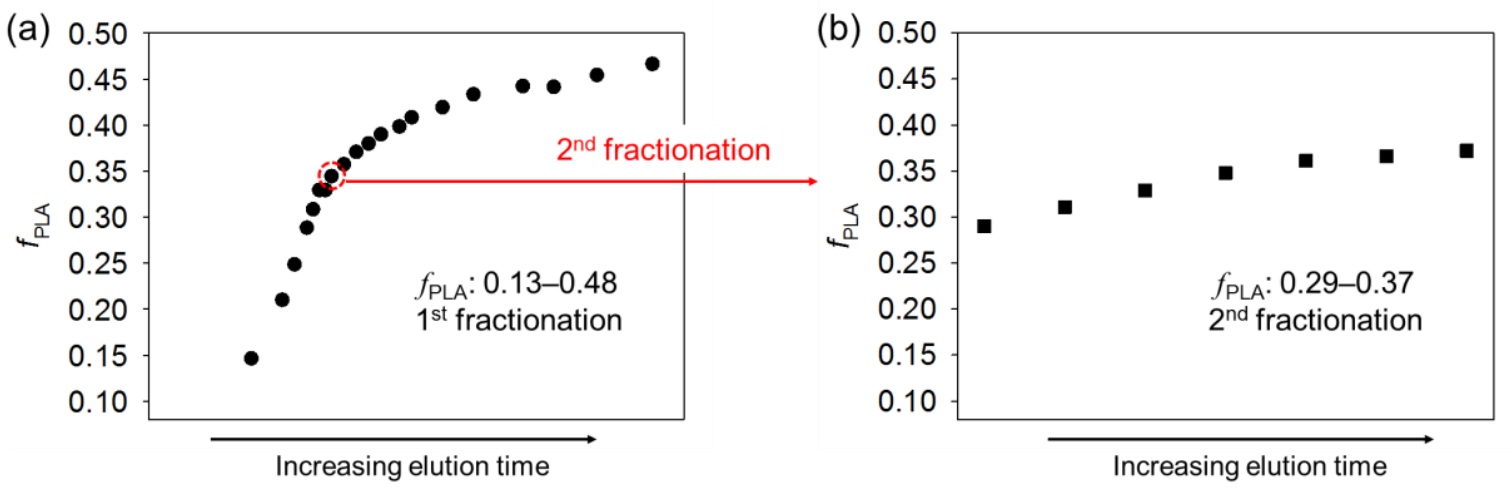

Figure S8. Characterizing the distribution in average composition of a fraction. (a) Parent PDDA- $b$-PLA $\left(\left\langle f_{\mathrm{PLA}}\right\rangle=0.34\right)$ and first fractions ranging from $f_{\mathrm{PLA}}=0.13-0.48$. (b) A second fractionation of the sample circled in red from part (a) $\left(M_{\mathrm{n}, \mathrm{BCP}}=4200 \mathrm{~g} / \mathrm{mol}, f_{\mathrm{PLA}}=0.35\right)$. The second fractionation results in a reduced range of $f_{\mathrm{PLA}}(0.29-0.37)$ as measured by ${ }^{1} \mathrm{H}$ NMR, which suggests a narrower composition distribution versus the as-synthesized BCP. 


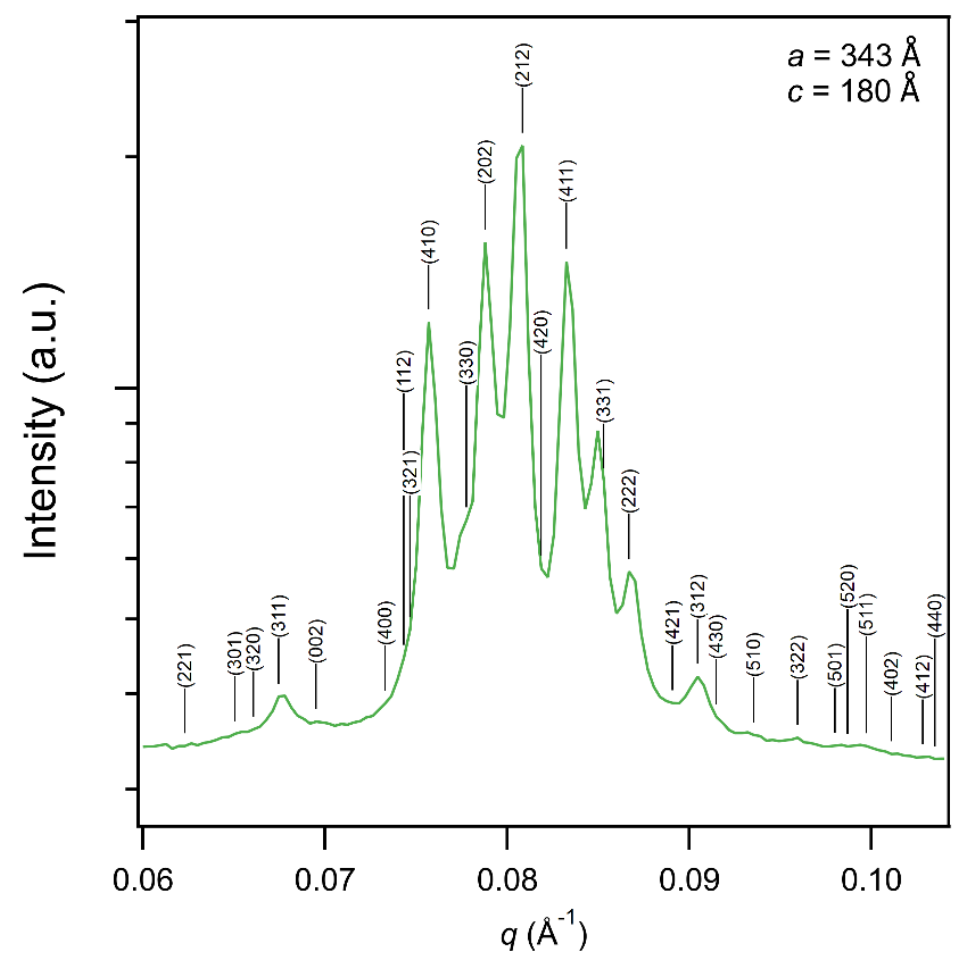

Figure S9. SAXS profile of fractionated PDDA- $b$-PLA $\left(f_{\mathrm{PLA}}=0.24\right)$ after $2 \mathrm{~h}$ annealing at $50{ }^{\circ} \mathrm{C}$ consistent with the $\sigma$ phase. All allowed reflections for space group $P 4_{2} / \mathrm{mnm}$ are demarcated with indices for $q=0.06-0.11 \AA^{-1}(a=343 \AA, c=180 \AA)$. The greater homogeneity of the fractionated sample produces large and well-ordered grains that contribute to anomalous peak intensities. ${ }^{2}$ 


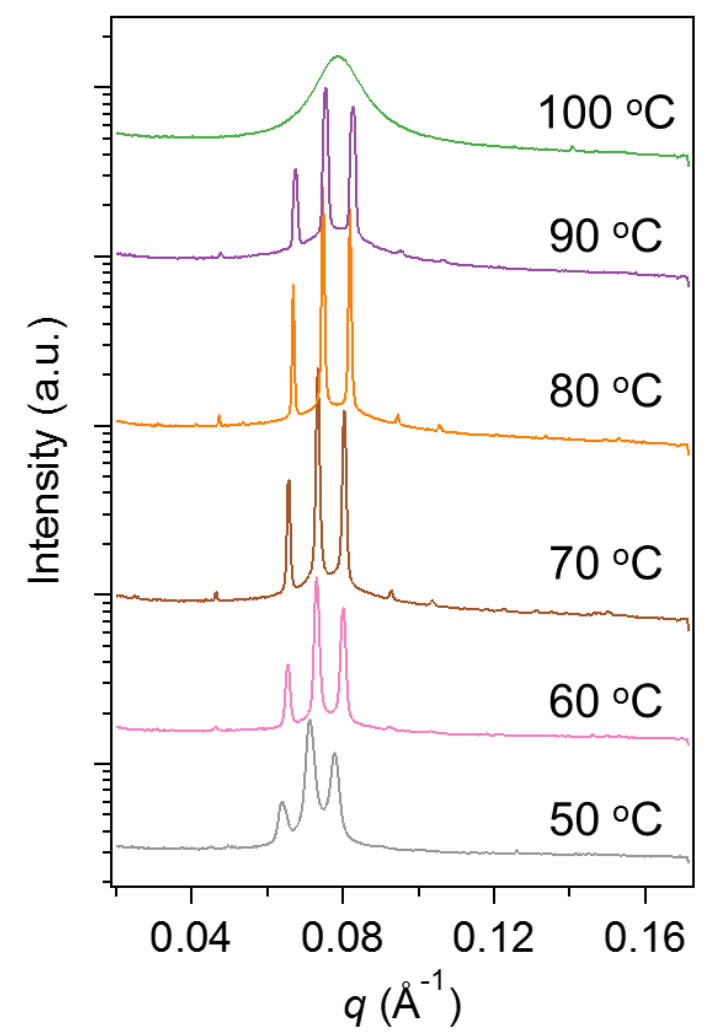

Figure S10. Variable-temperature synchrotron SAXS patterns of a fractionated PDDA- $b$-PLA diblock copolymer $\left(M_{\mathrm{n}, \mathrm{BCP}}=4000 \mathrm{~g} / \mathrm{mol}, f_{\mathrm{PLA}}=0.31\right)$ showing the order-disorder transition (ODT) between $90-100^{\circ} \mathrm{C}$.

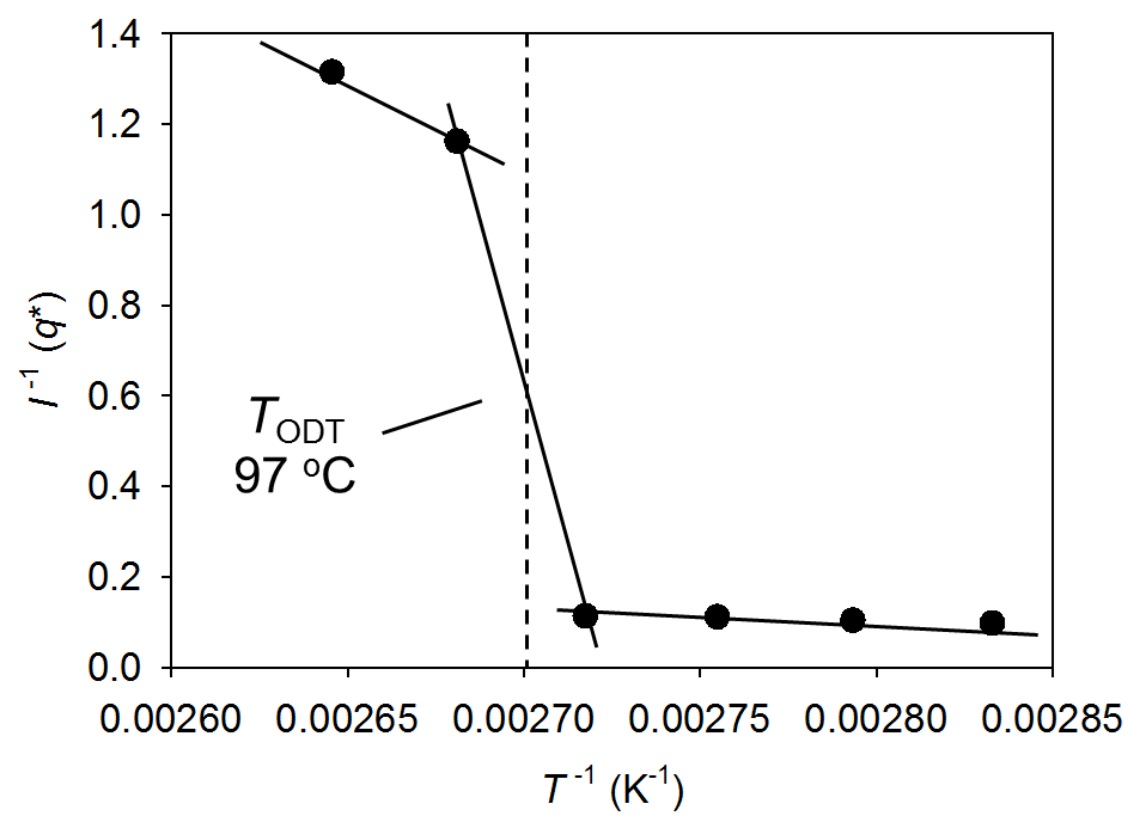

Figure S11. Representative analysis of the order-disorder transition temperature $\left(T_{\mathrm{ODT}}\right)$ of fractionated PDDA- $b$-PLA diblock copolymers determined on heating via the plot of inverse intensity of the primary SAXS peak $\left(I^{-1}\left(q^{*}\right)\right)$ versus inverse temperature $\left(T^{-1}\right)$. $T_{\text {ODT }}$ was identified as the midpoint of the discontinuity in $I^{-1}\left(q^{*}\right)$. Lines are drawn as guides to the eye. As depicted, $T_{\mathrm{ODT}}=97{ }^{\circ} \mathrm{C}$ for the fractionated sample with $M_{\mathrm{n}}=4000 \mathrm{~g} / \mathrm{mol}$ and $f_{\mathrm{PLA}}=0.31$. 


\section{Self-Consistent Field Theory (SCFT) methods}

\section{Dispersity model}

The dispersity model consists of five diblock chain types blended together. The distribution can then be described by 15 parameters: five PLA block lengths $N_{\mathrm{A} j}$, five PDDA block lengths $N_{\mathrm{B} j}$, and the number of each chain $n_{j}$, where $j \in[1,5]$. Based on the distribution results in Figure 1 we assume each chain has the same length of PDDA block $N_{\mathrm{B} j}=N_{\mathrm{B}} \forall j$, but that the PLA blocks have different lengths. The distribution of PLA lengths is symmetrical and peaked around the bulk composition, which can be represented mathematically by:

$$
\begin{gathered}
N_{\mathrm{A} 1}=N_{\mathrm{A}}\left(1-\delta_{1}\right) \\
N_{\mathrm{A} 2}=N_{\mathrm{A}}\left(1-\delta_{2}\right) \\
N_{\mathrm{A} 3}=N_{\mathrm{A}} \\
N_{\mathrm{A} 4}=N_{\mathrm{A}}\left(1+\delta_{2}\right) \\
N_{\mathrm{A} 5}=N_{\mathrm{A}}\left(1+\delta_{1}\right) \\
n_{1}=n_{5}=r_{1} n_{3} \\
n_{2}=n_{4}=r_{2} n_{3}
\end{gathered}
$$

The parameters $\delta_{1}$ and $\delta_{2}$ control the relative lengths of each polymer and represent the range of polymer lengths in the sample. The parameters $r_{1}$ and $r_{2}$ control the relative population of each species, which determines the shape of the distribution. By replotting the data from Figure 1 as mass fraction versus PLA block length, one can determine that appropriate values for these parameters are $\delta_{1}=0.4, \delta_{2}=0.2, r_{1}=0.25$, and $r_{2}=0.5$. Note that by using this convention, the volume-average chain composition, $\bar{f}_{\mathrm{A}}$, is equal to the chain composition of the middle length chain, $f_{\mathrm{A} 3}=\frac{N_{\mathrm{A} 3}}{N_{\mathrm{A} 3}+N_{\mathrm{B} 3}}$. We define the reference chain length $N=N_{\mathrm{A}}+N_{\mathrm{B}}$ so that the final model is described by the parameters $\chi N,\left\langle f_{\mathrm{A}}\right\rangle, \varepsilon$ which correspond to segregation strength, average chain composition, and segment asymmetry.

\section{Free-energy calculations}

All SCFT calculations were performed using the simulation methods described in the Supporting Information of our previous report, ${ }^{1}$ unless otherwise described. Figure S12a shows the free energy per chain in units of $k_{B} T$ for each phase and the compositions at which each phase is stable for a disperse diblock copolymer with $\chi N=40$ and $\varepsilon=3.0$. Figure S12b shows the same information for the monodisperse model. Note that SCFT predicts spheres on an FCC lattice as a stable structure at compositions between where DIS and BCC are stable, but the FCC phase is omitted in Figure S12 for clarity. The five diblock blend is also in principle capable of forming coexisting ordered phases, but ordered phase coexistence windows are typically very narrow and are not considered here. Figure S12 shows some of the same qualitative trends as observed in experiment (Figure 3): the stability windows for $\sigma$ and A15 are larger in the polydisperse system, and the BCC- $\sigma$ boundary shifts to lower $f_{\mathrm{A}}$ in the polydisperse system when compared to the monodisperse system. When compared to experiments, however, the SCFT results predict much smaller changes in the phase boundaries between polydisperse and monodisperse systems. The SCFT also predicts that the HEX phase stability window decreases, which is not observed experimentally. These inconsistencies between SCFT and experiment might be a consequence of the continuous Gaussian chain 
model that was employed in SCFT: The experimental system has degrees of polymerization less than 100, while the continuous Gaussian chain model is only appropriate for modelling very long polymer chains.
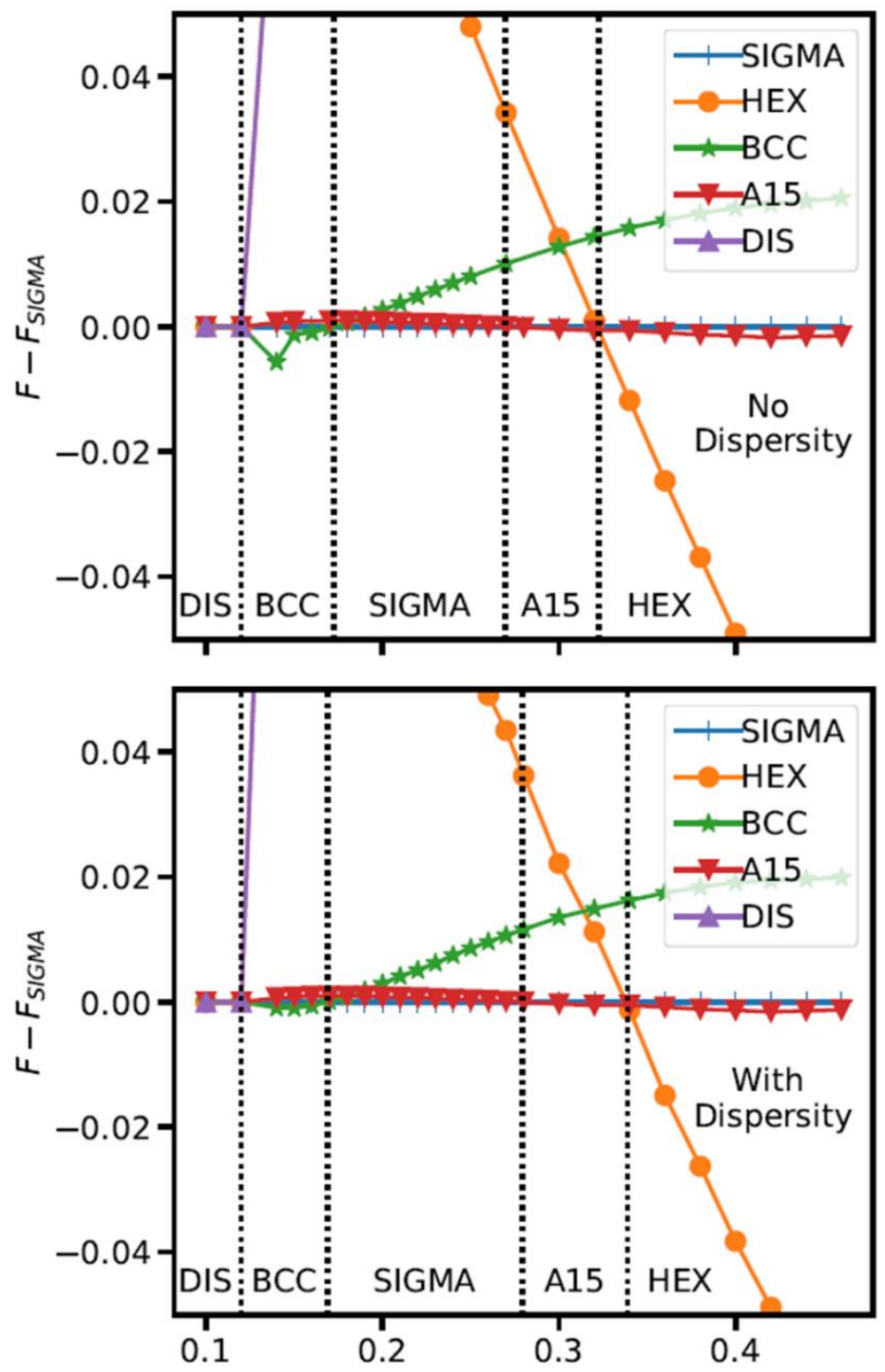

Figure S12. Free energies relative to the DIS phase of experimentally observed phases formed by (a) a five species diblock blend and (b) monodisperse diblocks as a function of composition $\left\langle f_{\mathrm{A}}\right\rangle$ or $f_{\mathrm{A}}$.

\section{Chain partitioning analysis methodology}

The analysis of chain partitioning into symmetry distinct domains is performed by first identifying spheres using a "burning algorithm" described in the Supporting Information of our previous report ${ }^{3}$ and determining the center of mass of each sphere. A Voronoi cell is then constructed for each sphere center of mass and the average density of PLA is computed in the cell. The average density of PLA contributed by each chain is also computed for each Voronoi cell. If chains are distributed uniformly between spheres then the fraction of PLA density contributed by chain $j$ will be 


$$
E_{j}=\frac{n_{j} N_{\mathrm{A} j}}{\sum_{i=1}^{5} n_{i} N_{\mathrm{A} i}}
$$

We compare this expected value, $E_{j}$, to the value calculated from the SCFT simulation, $M_{j}$, and compute the percent enrichment, $R_{j}$, as

$$
R_{j}=\frac{M_{j}-E_{j}}{E_{j}}
$$

The percent enrichment values are reported in Table S3. These values were calculated at $\left\langle f_{\mathrm{A}}\right\rangle=0.24$ for all phases. Table $\mathbf{S 3}$ shows that the $\sigma$ phase has the strongest partitioning of chains between different sphere types. The $2 \mathrm{~b}$ Wyckoff position has the most enrichment of short chains (Chain 1 and 2) of any sphere at $6.59 \%$ and $4.58 \%$ and also shows significant depletion of long chains (Chain 4 and 5 ) at $-2 \%$ and $-8.18 \%$. The $4 \mathrm{f}$ Wyckoff position on the other hand has the most depletion of short chains while showing the greatest enrichment in long chains. For the A15 phase, the 2a Wyckoff position shows enrichment of short chains and depletion of long chains, and the $6 \mathrm{~d}$ position shows enrichment of long chains and depletion of short chains, but to a lesser degree than in the $\sigma$ phase.

Table S4. Percent enrichment of each chain type in each unique sphere. The degree of partitioning, measured via the deviation in sphere composition from bulk composition, follows the same order as the changes in free energy: the $\sigma$ phase shows the most partitioning, followed by A15, while HEX and BCC are incapable of partitioning as all micelles are identical.

\begin{tabular}{crrrrr}
\hline \multirow{2}{*}{$\begin{array}{c}\text { Phase/Sphere } \\
\text { Wyckoff Position }\end{array}$} & \multicolumn{5}{c}{ Percent Enrichment } \\
\cline { 2 - 6 }- & Chain 1 & Chain 2 & Chain 3 & Chain 4 & Chain 5 \\
\hline$\sigma / 2 b$ & $6.59 \%$ & $4.58 \%$ & $1.24 \%$ & $-2.00 \%$ & $-8.18 \%$ \\
$\sigma / 8 i$ & $5.44 \%$ & $3.72 \%$ & $1.05 \%$ & $-1.44 \%$ & $-7.10 \%$ \\
$\sigma / 8 i^{\prime}$ & $-4.51 \%$ & $-2.10 \%$ & $-0.19 \%$ & $2.48 \%$ & $0.63 \%$ \\
$\sigma / 8 j$ & $-4.72 \%$ & $-2.01 \%$ & $-0.14 \%$ & $2.44 \%$ & $0.53 \%$ \\
$\sigma / 4 f$ & $-8.51 \%$ & $-4.64 \%$ & $-0.81 \%$ & $4.17 \%$ & $4.12 \%$ \\
$\mathrm{~A} 15 / 2 a$ & $4.85 \%$ & $3.15 \%$ & $0.88 \%$ & $-1.08 \%$ & $-6.34 \%$ \\
$\mathrm{~A} 15 / 6 d$ & $-4.25 \%$ & $-1.83 \%$ & $-0.13 \%$ & $2.31 \%$ & $0.31 \%$ \\
\hline
\end{tabular}




\section{Synthesis and fractionation of PDMS- $b$-PLA diblock copolymer.}<smiles>CC1OC(=O)C(C)OC1=O</smiles><smiles>CC(C)(C)O[Si](C)(C)C(C)(C)O[Si](C)(C)CCCO</smiles><smiles>CC(O)C(=O)OCCCCCCC(C)(C)[Si](C)(C)OC(C)(C)[Si](C)(C)C</smiles>

$100^{\circ} \mathrm{C}$

In a nitrogen filled glovebox, $4.50 \mathrm{~g}$ of $( \pm)$-lactide $(31.25 \mathrm{mmol}, 24.51 \mathrm{eq}), 1.275 \mathrm{~g}$ of monocarbinol terminated PDMS (2.57 mmol, $1 \mathrm{eq}), 2.4 \mathrm{mg}$ of Sn(Oct) $(0.043 \mathrm{mmol}, 0.017$ eq), and $21 \mathrm{ml}$ of anhydrous toluene were combined in an oven-dried heavy wall pressure vessel with a stir bar. The vessel was sealed with a threaded PTFE bushing using a perfluoro O-ring and removed from the glovebox. The vessel was placed in an oil bath at $100{ }^{\circ} \mathrm{C}$ and stirred for 150 minutes. After removal from the oil bath, the vessel was immediately quenched in an ice water bath. An aliquot was removed to determine the monomer conversion by ${ }^{1} \mathrm{H}$ NMR $(82 \%)$. Solvent was removed in vacuo and the polymer was redissolved in dichloromethane, run through a plug of basic alumina, and precipitated into hexanes.

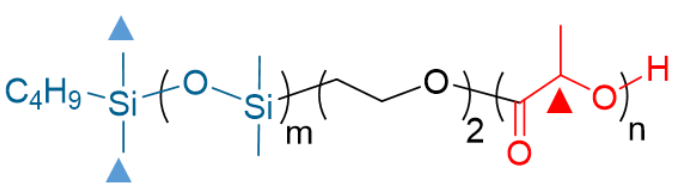

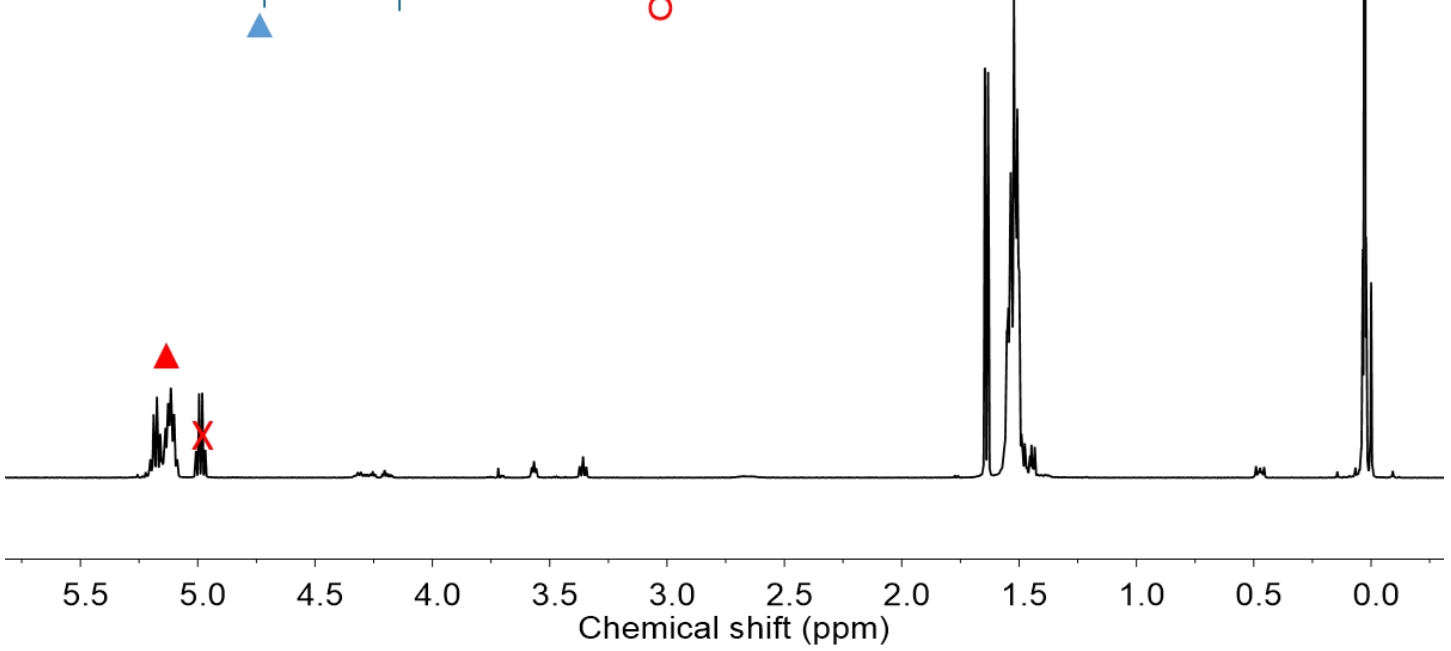

Figure S13. ${ }^{1} \mathrm{H}$ NMR spectrum of PDMS- $b$-PLA diblock copolymer with characteristic resonances used to calculate composition indicated by triangles. $X$ indicates residual $( \pm)$ lactide monomer. 
Table S5. Molecular characterization data for PDMS- $b$-PLA diblock copolymer.

\begin{tabular}{cccccccccc}
\hline$D P_{\mathrm{PLA}^{\mathrm{a}}}$ & $D P_{\mathrm{PDMS}^{\mathrm{a}}}$ & $\begin{array}{c}M_{\mathrm{n}, \mathrm{PLA}} \\
(\mathrm{g} / \mathrm{mol})^{a}\end{array}$ & $\begin{array}{c}M_{\mathrm{n}, \mathrm{PDMS}} \\
(\mathrm{g} / \mathrm{mol})^{a}\end{array}$ & $\begin{array}{c}M_{\mathrm{n}, \mathrm{BCP}} \\
(\mathrm{g} / \mathrm{mol})^{b}\end{array}$ & $D^{b}$ & $f_{\mathrm{PLA}^{c}}$ & $N^{d}$ & $\begin{array}{c}T_{\mathrm{ODT}} \\
\left({ }^{\circ} \mathrm{C}\right)^{e}\end{array}$ & Phase $^{f}$ \\
\hline 62 & 20 & 4500 & 1500 & 9200 & 1.08 & 0.70 & 73 & - & DIS \\
\hline
\end{tabular}

${ }^{a}$ Degree of polymerization (DP) and number-average molar mass of each block calculated from ${ }^{1} \mathrm{H}$ NMR end-group analysis. ${ }^{b}$ Molar mass and dispersity determined using SEC and conventional calibration analysis in chloroform relative to PS standards. ${ }^{c}$ Volume fraction of PLA based on reported homopolymer densities at $25{ }^{\circ} \mathrm{C}\left(0.95\right.$ and $1.25 \mathrm{~g} / \mathrm{cm}^{3}$ for PDMS and PLA, respectively) and ${ }^{1} \mathrm{H}$ NMR. ${ }^{d}$ Volumetric degree of polymerization based on reported homopolymer densities and a reference volume $v_{0}=118 \AA^{3}$. ${ }^{e}$ No order-disorder transition temperature was observed. ${ }^{f}$ Phase as determined by SAXS at $25^{\circ} \mathrm{C}$.

Table S6. Gradient profile for PDMS- $b$-PLA separation (eluent: hexane/ethyl acetate).

\begin{tabular}{ccc}
\hline \%EtOAc (start) & \%EtOAc (end) & Column Volume $(\mathrm{CV})$ \\
\hline 0 & 0 & 1 \\
0 & 60 & 3 \\
60 & 60 & 5 \\
\hline
\end{tabular}


(a)
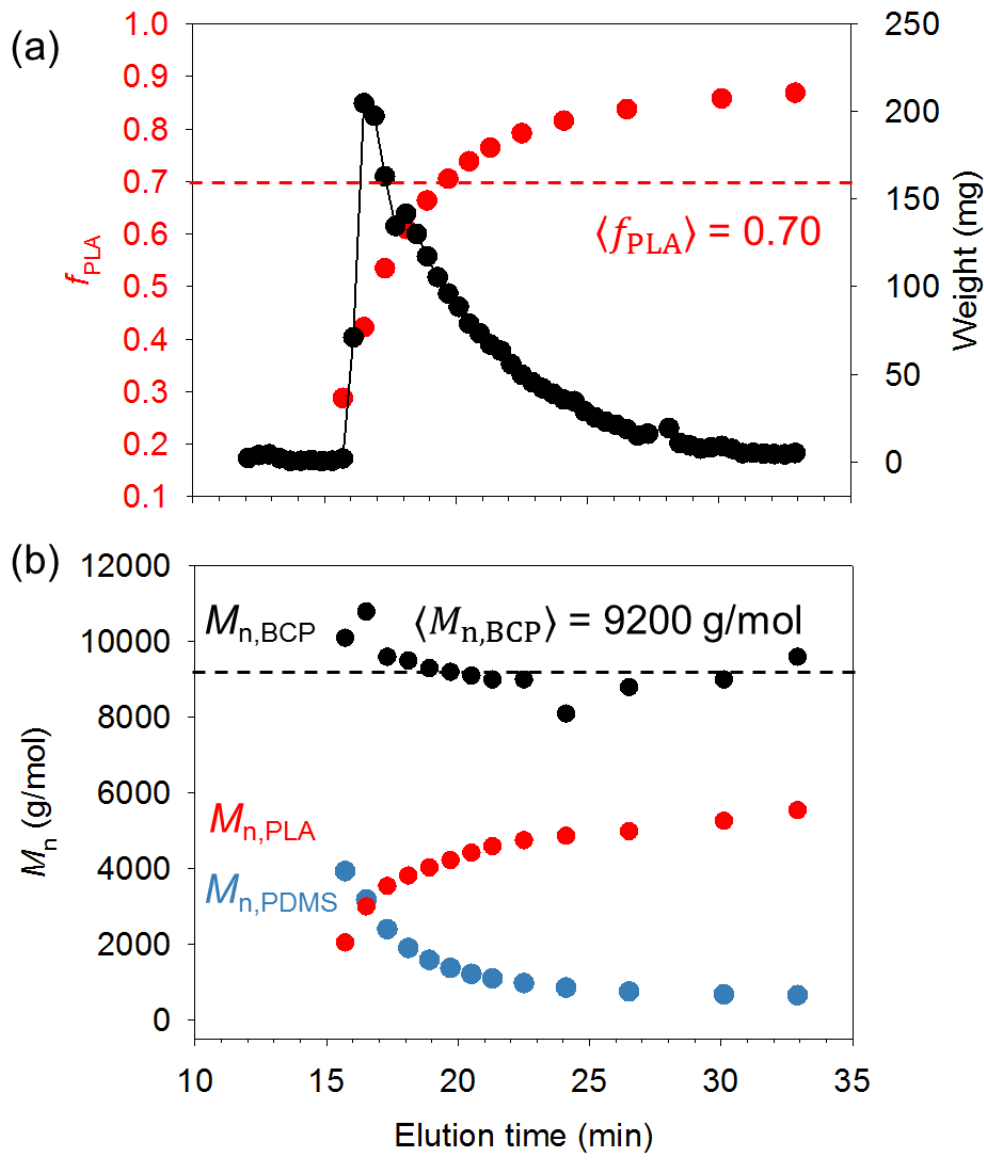

Figure S14. Chromatographic fractionation of PDMS- $b$-PLA diblock copolymer $\left(\left\langle M_{\mathrm{n}, \mathrm{BCP}}\right\rangle=\right.$ $9200 \mathrm{~g} / \mathrm{mol},\left\langle f_{\mathrm{PLA}}\right\rangle=0.70$ ). (a) Dependence of mass recovery and $f_{\mathrm{PLA}}$ on elution time. The red dashed line represents $f_{\text {PLA }}$ before separation. The total mass recovery was $88 \%$. (b) Changes in molecular weight of PDMS $\left(M_{\mathrm{n}, \mathrm{PDMS}}\right)$, PLA $\left(M_{\mathrm{n}, \mathrm{PLA}}\right)$, and the block copolymer $\left(M_{\mathrm{n}, \mathrm{BCP}}\right)$. 


\section{Synthesis and fractionation of PtBS- $b$-PMMA diblock copolymer}

Synthetic details can be found in a previous report. ${ }^{4}$

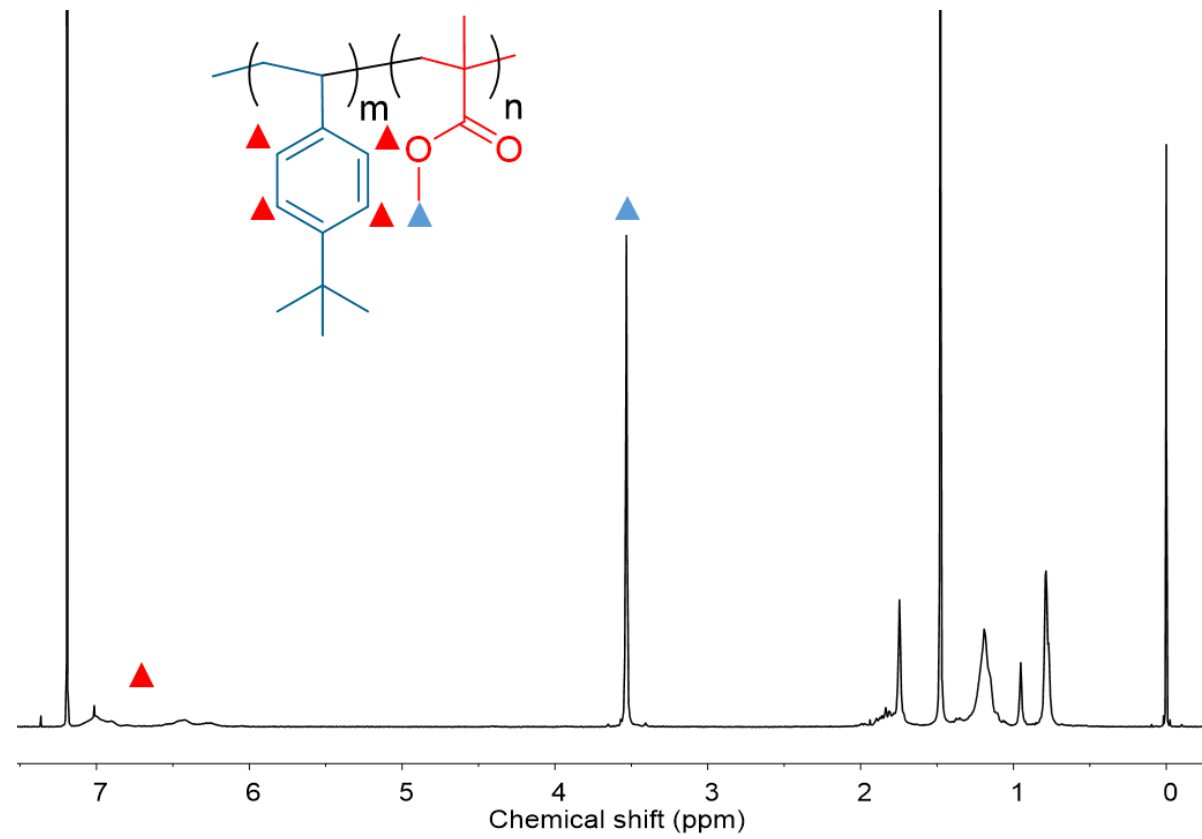

Figure S15. ${ }^{1} \mathrm{H}$ NMR spectrum of PtBS- $b$-PMMA diblock copolymer with characteristic resonances used to calculate composition indicated by triangles.

Table S7. Molecular characterization data for PtBS- $b$-PMMA diblock copolymer.

\begin{tabular}{cccccccccc}
\hline$D P_{\mathrm{PtBS}^{\mathrm{a}}}$ & $D P_{\mathrm{PMMA}^{\mathrm{a}}}$ & $\begin{array}{c}M_{\mathrm{n}, \mathrm{PtBS}} \\
(\mathrm{g} / \mathrm{mol})^{a}\end{array}$ & $\begin{array}{c}M_{\mathrm{n}, \mathrm{PMMA}} \\
(\mathrm{g} / \mathrm{mol})^{a}\end{array}$ & $\begin{array}{c}M_{\mathrm{n}, \mathrm{BCP}} \\
(\mathrm{g} / \mathrm{mol})^{b}\end{array}$ & $\Xi^{b}$ & $f_{\mathrm{MMA}^{c}}$ & $N^{d}$ & $\begin{array}{c}T_{\mathrm{ODT}} \\
\left({ }^{\circ} \mathrm{C}\right)^{e}\end{array}$ & Phase $^{f}$ \\
\hline 94 & 280 & 15500 & 28000 & 39300 & 1.02 & 0.60 & 559 & $>150$ & LAM \\
\hline
\end{tabular}

${ }^{a}$ Degree of polymerization (DP) and number-average molar mass of each block calculated from ${ }^{1} \mathrm{H}$ NMR end-group analysis. ${ }^{b}$ Molar mass and dispersity determined using SEC with conventional calibration in THF relative to PS standards. ${ }^{c}$ Volume fraction of PMMA based on reported homopolymer densities $25{ }^{\circ} \mathrm{C}\left(0.95\right.$ and $1.18 \mathrm{~g} / \mathrm{cm}^{3}$ for PtBS and PMMA, respectively) ${ }^{4}$ and ${ }^{1} \mathrm{H}$ NMR. ${ }^{d}$ Volumetric degree of polymerization based on reported homopolymer densities and a reference volume $v_{0}=118 \AA^{3}$. ${ }^{e}$ The $T_{\mathrm{ODT}}$ is above $150{ }^{\circ} \mathrm{C}$. ${ }^{\mathrm{P}} \mathrm{Ph}$ ase was determined using in-house SAXS at $25^{\circ} \mathrm{C}$.

Table S8. Gradient profile for PtBS- $b$-PMMA separation (eluent: hexane/THF).

\begin{tabular}{ccc}
\hline \% THF (start) & \% THF (end) & Column Volume (CV) \\
\hline 0 & 20 & 2 \\
20 & 75 & 3 \\
75 & 75 & 5 \\
\hline
\end{tabular}




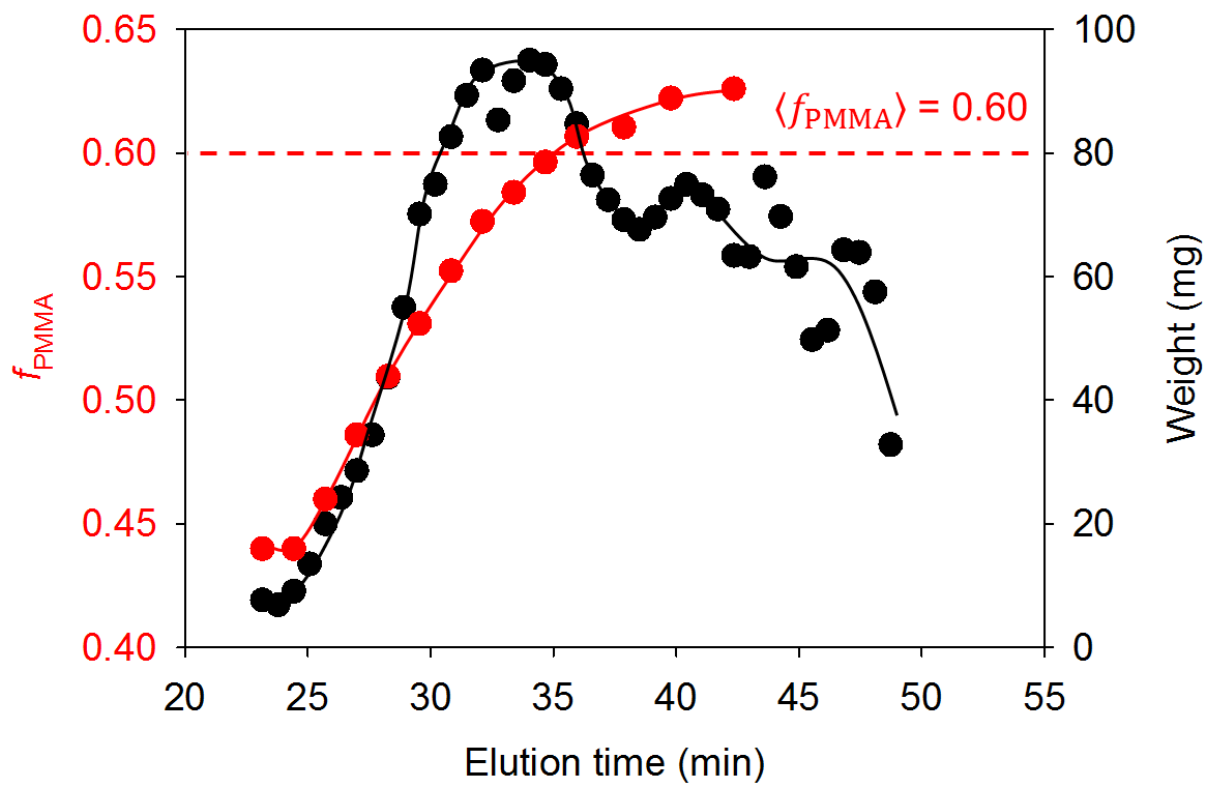

Figure S16. Chromatographic fractionation of parent P $t$ BS- $b$-PMMA diblock copolymer. The total mass recovery was $82 \%$.

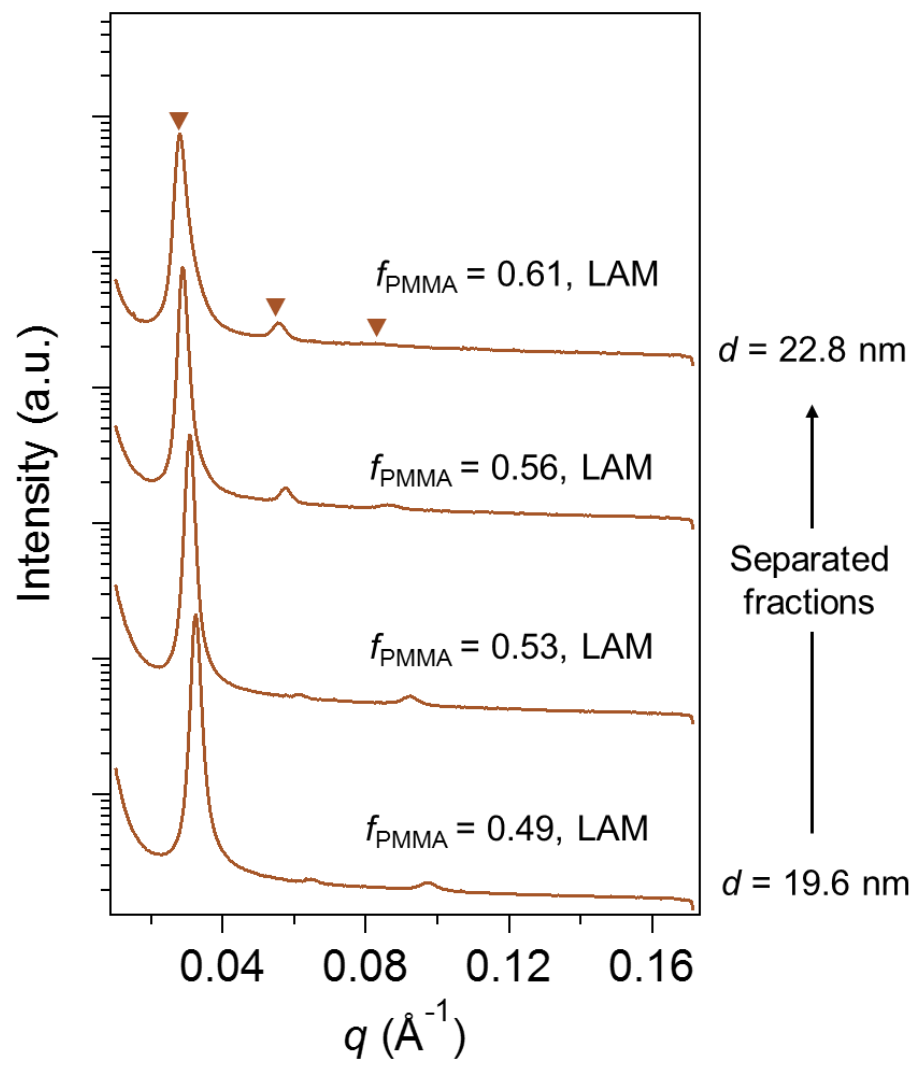

Figure S17. Representative synchrotron SAXS profiles of the fractionated PtBS- $b$-PMMA diblock copolymers with increasing $f_{\mathrm{PMMA}}$ at room temperature. 


\section{Synthesis and fractionation of PTFEA- $b$-PDDA diblock copolymer}

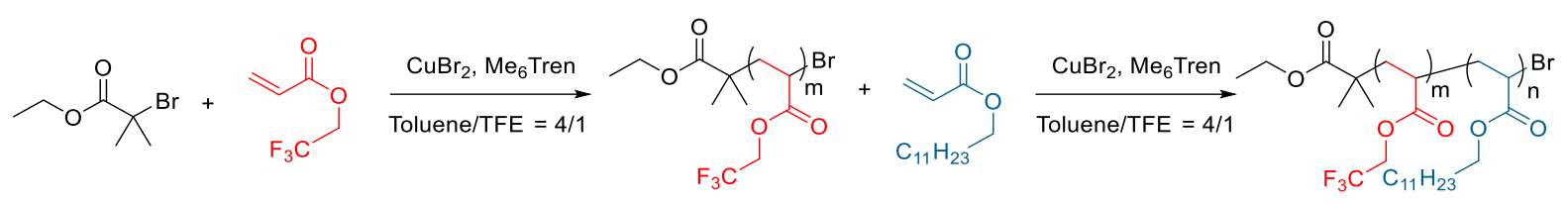

In a typical experiment, a solution of copper(II) bromide (14.0 mg, $0.062 \mathrm{mmol})$ and $\mathrm{Me}_{6}$ Tren $(86.0 \mathrm{mg}, 100.0 \mu \mathrm{L}, 0.38 \mathrm{mmol}$ ) was prepared in $1.0 \mathrm{~mL}$ of trifluoroethanol (TFE). In a scintillation vial, trifluoroethyl acrylate $(5.76 \mathrm{~g}, 37.4 \mathrm{mmol})$ was dissolved in a mixture of 4.6 $\mathrm{mL}$ toluene and $1.2 \mathrm{~mL}$ trifluoroethanol $\left(\mathrm{Cu}(\mathrm{II}) / \mathrm{Me}_{6}\right.$ Tren stock solution, $373 \mu \mathrm{L}$ ). Ethyl $\alpha-$ bromoisobutyrate $(0.23 \mathrm{~g}, 1.17 \mathrm{mmol})$ was then added, the vial was capped with a septum, and the solution was degassed with argon for 15 minutes. With stirring, the polymerization mixture was then irradiated $(\lambda \approx 360 \mathrm{~nm})$ for 5 hours in a commercial UV nail lamp system until $70 \%$ conversion was achieved as monitored by ${ }^{1} \mathrm{H}$ NMR. The resulting PTFEA $\left(M_{\mathrm{n}}=3,400 \mathrm{~g} / \mathrm{mol}\right)$ was purified via dissolution in a minimal amount of toluene and precipitated in cold hexanes three times.

For the preparation of a diblock copolymer, in a scintillation vial, dodecyl acrylate $(4.3 \mathrm{~g}, 17.9$ mmol) was dissolved in a mixture of $5.0 \mathrm{~mL}$ toluene and $1.3 \mathrm{~mL}$ trifluoroethanol $\left(\mathrm{Cu}(\mathrm{II}) / \mathrm{Me}_{6}\right.$ Tren stock solution, $\left.186 \mu \mathrm{L}\right)$. Previously prepared PTFEA macroinitiator $(2.0 \mathrm{~g}$, $0.59 \mathrm{mmol}$ ) was then added, the vial capped with a septum, and the solution degassed with argon for 10 minutes. With stirring, the polymerization mixture was irradiated $(\lambda \approx 360 \mathrm{~nm})$ for 3 hours in a commercial UV nail lamp system until $70 \%$ conversion was achieved as monitored by ${ }^{1} \mathrm{H}$ NMR. The resulting PTFEA- $b$-PDDA diblock copolymer was purified via dissolution in a minimal amount of toluene and precipitated in cold methanol three times.

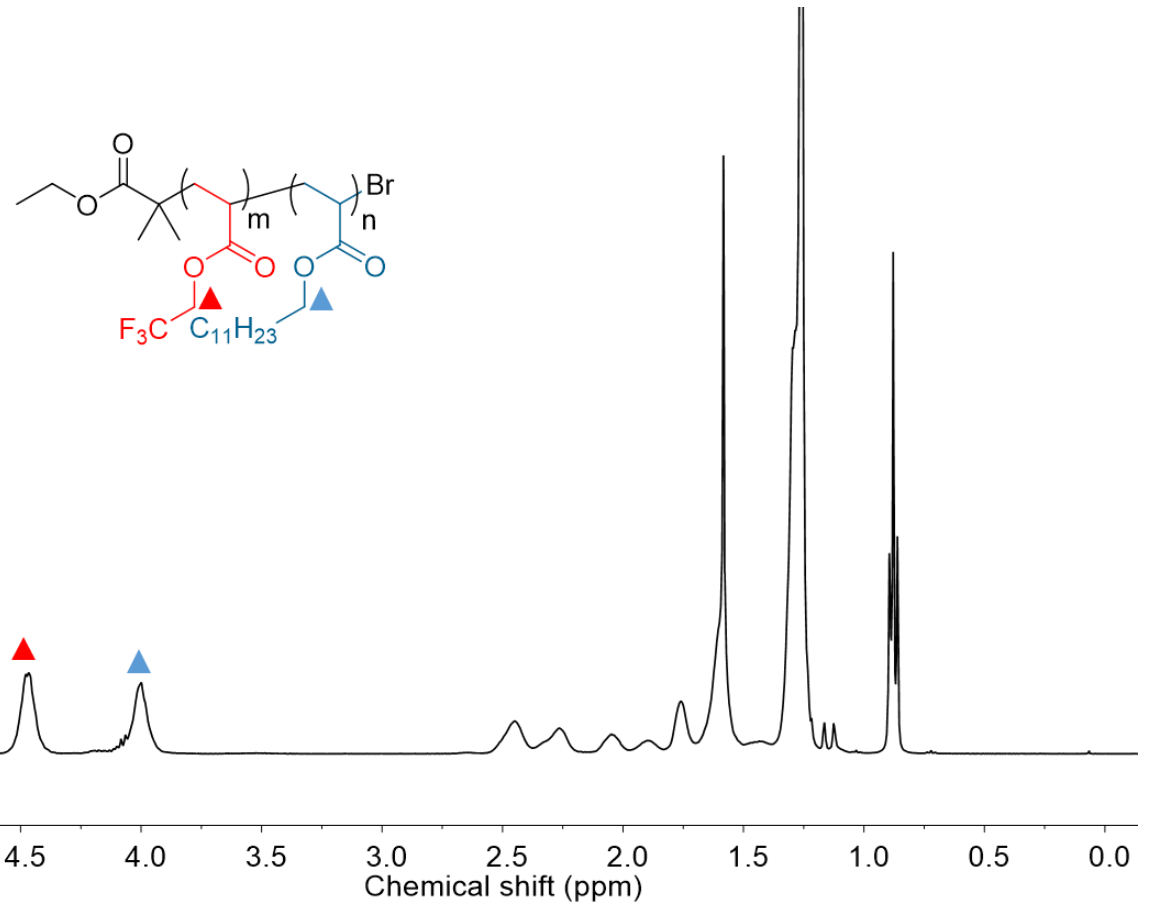

Figure S18. ${ }^{1} \mathrm{H}$ NMR spectrum of PTFEA- $b$-PDDA diblock copolymer with characteristic resonances used to calculate composition marked by triangles. 
Table S9. Molecular characterization data for PTFEA- $b$-PDDA diblock copolymer.

\begin{tabular}{cccccccccc}
\hline$D P_{\text {PDDA }^{\mathrm{a}}}$ & $D P_{\text {PTFEA }^{\mathrm{a}}}$ & $\begin{array}{c}M_{\mathrm{n}, \mathrm{PDDA}} \\
(\mathrm{g} / \mathrm{mol})^{a}\end{array}$ & $\begin{array}{c}M_{\mathrm{n}, \mathrm{PTFEA}} \\
(\mathrm{g} / \mathrm{mol})^{a}\end{array}$ & $\begin{array}{c}M_{\mathrm{n}, \mathrm{BCP}} \\
(\mathrm{g} / \mathrm{mol})^{b}\end{array}$ & $Ð^{b}$ & $f_{\mathrm{PTFEA}^{c}}$ & $N^{d}$ & $\begin{array}{c}T_{\mathrm{ODT}} \\
\left({ }^{\circ} \mathrm{C}\right)^{e}\end{array}$ & Phase $^{f}$ \\
\hline 21 & 22 & 5100 & 3400 & 8400 & 1.06 & 0.31 & 111 & 150 & $\mathrm{HEX}$ \\
\hline
\end{tabular}

${ }^{a}$ Degree of polymerization (DP) and number-average molar mass of each block calculated from ${ }^{1} \mathrm{H}$ NMR end-group analysis. ${ }^{b}$ Molar mass and dispersity determined using SEC-MALLS in THF. ${ }^{c}$ Volume fraction of PTFEA based on reported homopolymer densities at $25^{\circ} \mathrm{C}(0.94$ and $1.403 \mathrm{~g} / \mathrm{cm}^{3}$ for PDDA and PTFEA, respectively) and ${ }^{1} \mathrm{H}$ NMR. ${ }^{d}$ Volumetric degree of polymerization based on reported homopolymer densities and a reference volume, $v_{0}=118 \AA^{3}$. ${ }^{e}$ Order-disorder transition temperature determined from rheology performed on heating at a rate of $1{ }^{\circ} \mathrm{C} / \mathrm{min}$. ${ }^{f}$ Phase as determined by SAXS at $T<T_{\text {ODT }}$.

Table S10. Gradient profile for PTFEA- $b$-PDDA separation (eluent: hexane/ethyl acetate).

\begin{tabular}{ccc}
\hline \%EtOAc (start) & \%EtOAc (end) & Column Volume (CV) \\
\hline 0 & 0 & 4 \\
0 & 22 & 5 \\
22 & 22 & 5 \\
\hline
\end{tabular}




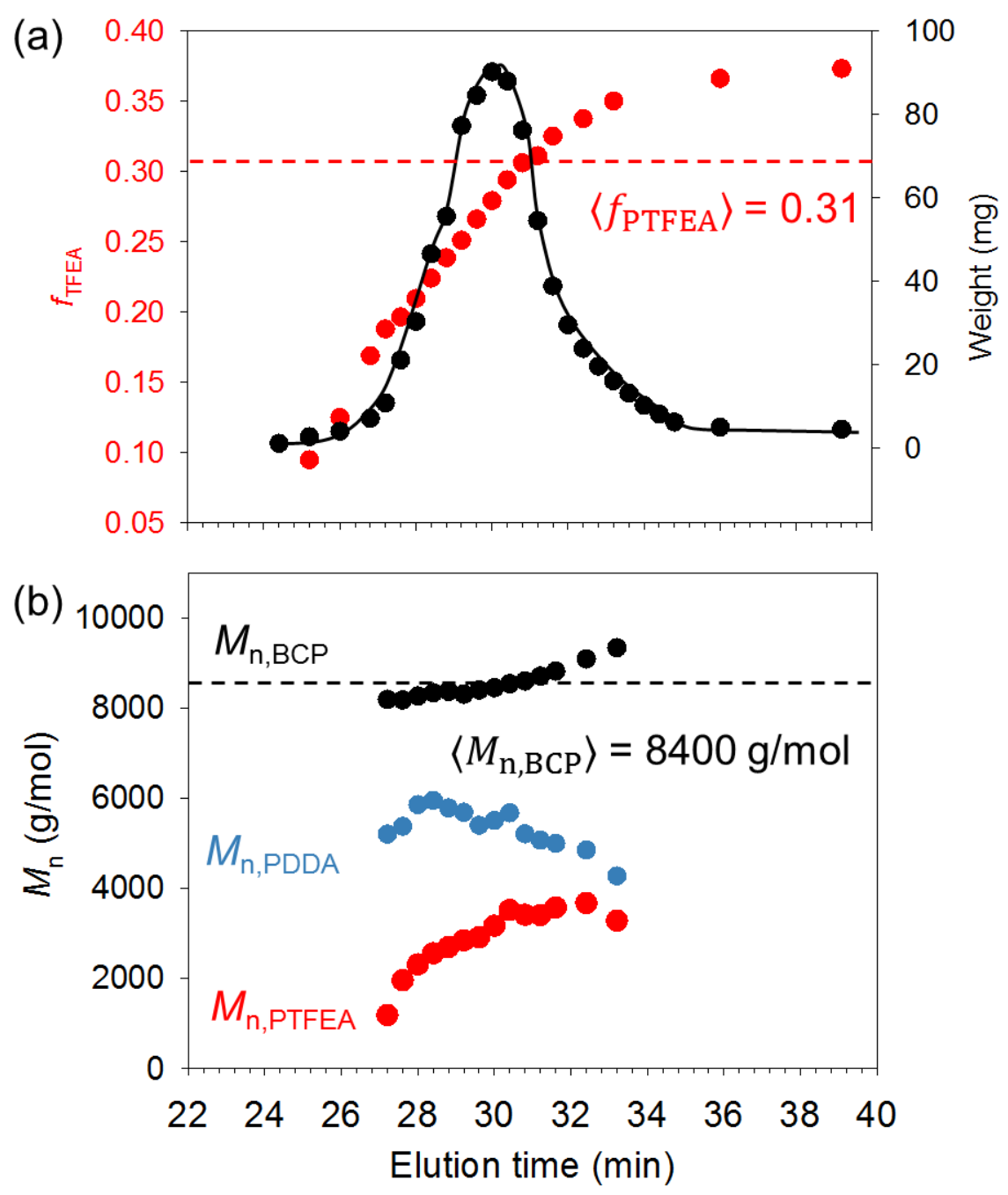

Figure S19. Chromatographic fractionation of a PTFEA- $b$-PDDA diblock copolymer $\left(\left\langle M_{\mathrm{n}, \mathrm{BCP}}\right\rangle=8400 \mathrm{~g} / \mathrm{mol},\left\langle f_{\mathrm{PTFEA}}\right\rangle=0.31\right)$. (a) Dependence of mass recovery and $f_{\text {PTFEA }}$ on elution time. The red dashed line represents $f_{\text {PTFEA }}$ before separation. The total mass recovery was $88 \%$. (b) Changes in molecular weight of PDDA $\left(M_{\mathrm{n}, \mathrm{PDDA}}, \mathrm{NMR}\right)$, PTFEA $\left(M_{\mathrm{n}, \mathrm{PTFEA}}\right.$, $\mathrm{NMR})$, and the block copolymer $\left(M_{\mathrm{n}, \mathrm{BCP}}, \mathrm{SEC}\right)$.

\section{Synthesis and fractionation of PTFEA- $b$-PDMOA diblock copolymers}
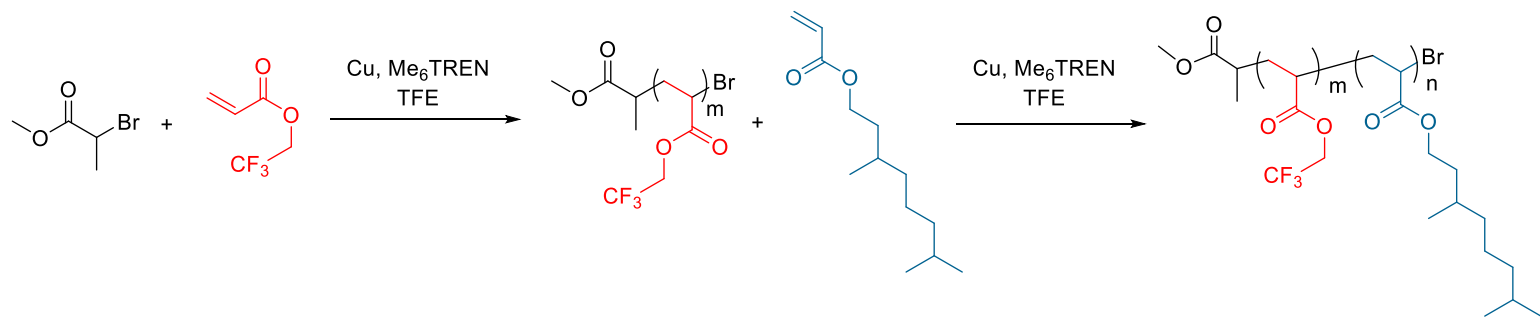

A solution of trifluoroethyl acrylate $(2.0 \mathrm{~g}, 12.6 \mathrm{mmol})$, TFE $(2 \mathrm{~mL}), \mathrm{Me}_{6} \mathrm{TREN}(30 \mu \mathrm{L}, 0.27$ $\mathrm{mol})$, and methyl 2-bromopropionate $(56 \mu \mathrm{L}, 0.5 \mathrm{mmol})$ was prepared in a $20 \mathrm{~mL}$ scintillation vial. Oxygen was removed by degassing with argon for $10 \mathrm{~min}$. Subsequently, $2.5 \mathrm{~cm}$ of preactivated $\mathrm{Cu}(0)$ wire of 20 gauge wrapped around a Teflon-coated stirring bar was added under positive argon pressure. The solution was then degassed for an additional $5 \mathrm{~min}$. To monitor 
the monomer conversion, drops of sample were extracted using an airtight syringe. Samples were dissolved in $\mathrm{CDCl}_{3}$ to determine the monomer conversion by ${ }^{1} \mathrm{H} \mathrm{NMR}$ spectroscopy. The $M_{\mathrm{n}}$ and $M_{\mathrm{w}} / M_{\mathrm{n}}$ values were determined by size-exclusion chromatography with polystyrene standards. After $95 \%$ conversion was achieved for the first block at room temperature after 16 hours, a mixture of dimethyloctanyl acrylate ( $3.0 \mathrm{~g}, 14 \mathrm{mmol})$, TFE (2 mL), and Me 6 TREN (30 $\mu \mathrm{L}, 0.27 \mathrm{~mol}$ ) was prepared, degassed with argon for $10 \mathrm{~min}$, and then directly injected into the scintillation vial. After stirring at room temperature for $24 \mathrm{~h}$, the conversion of DMOA was determined. To stop the reaction, the vial was opened to air, and the polymerization mixture was dissolved in $2 \mathrm{~mL}$ of $\mathrm{CH}_{2} \mathrm{Cl}_{2}$. The resulting solution was precipitated in $50 \mathrm{~mL}$ of $\mathrm{MeOH}$ with vigorous stirring. The solvent was removed by filtration, and the final polymer was dried under vacuum. The copolymer chains that were capped with bromine atoms at the $\omega$-terminus was determined to be almost quantitative by the ratio between characteristic signals of both $\alpha$ (methyl peaks from initiator) and $\omega$ polymer terminus.

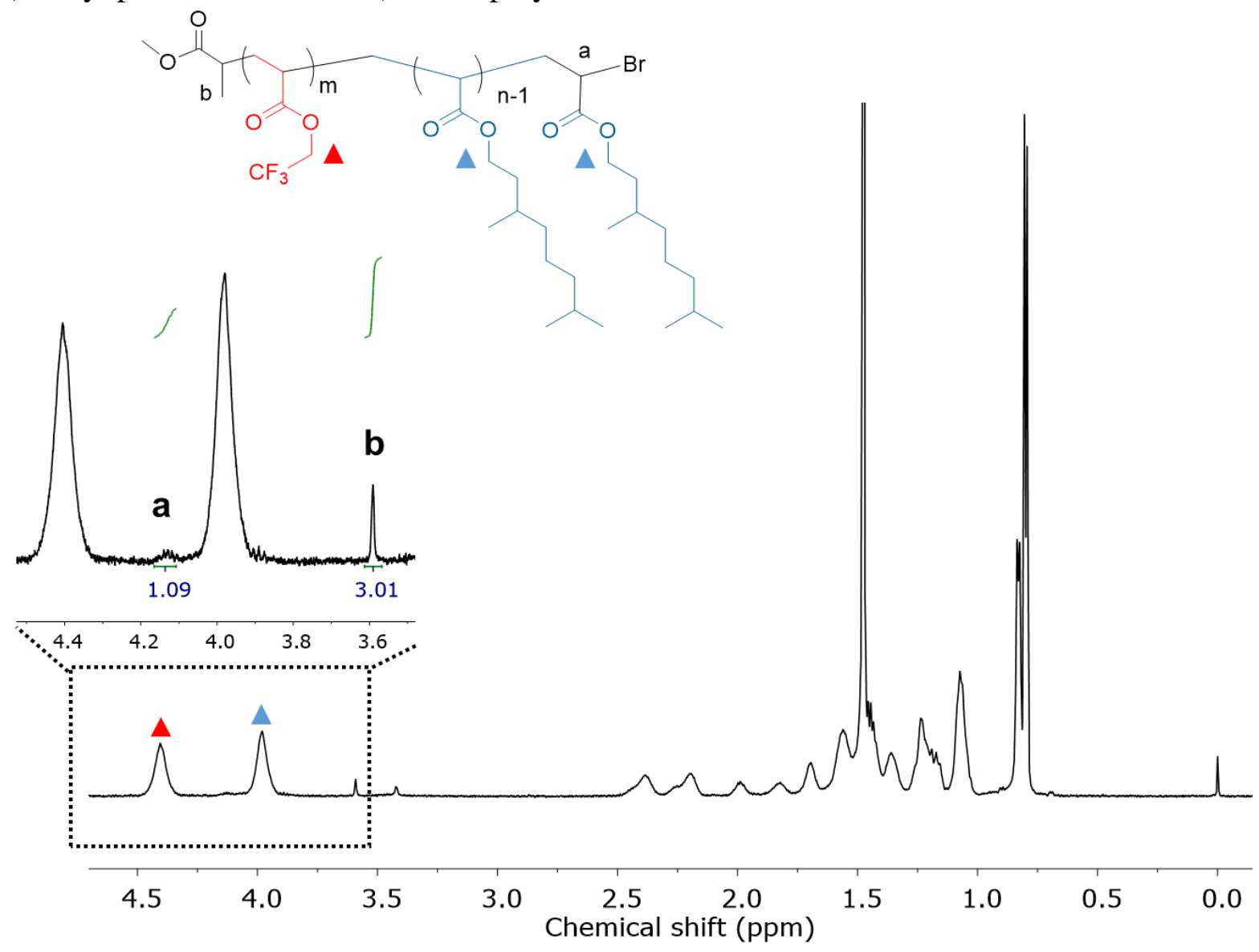

Figure S20. ${ }^{1} \mathrm{H}$ NMR spectrum of PTFEA- $b$-PDMOA diblock copolymer with characteristic resonances used to calculate composition indicated by triangles. Resonances of chain end $\mathbf{a}$ and $\mathbf{b}$ were used to calculate chain end fidelity. 
Table S11. Molecular characterization data for PTFEA- $b$-PDMOA diblock copolymer.

\begin{tabular}{cccccccccc}
\hline$D P_{\mathrm{PDMOA}^{\mathrm{a}}}$ & $D P_{\mathrm{PTFEA}^{\mathrm{a}}}$ & $\begin{array}{c}M_{\mathrm{n}, \mathrm{PMnA}} \\
(\mathrm{g} / \mathrm{mol})^{a}\end{array}$ & $\begin{array}{c}M_{\mathrm{n}, \mathrm{PTFEA}} \\
(\mathrm{g} / \mathrm{mol})^{a}\end{array}$ & $\begin{array}{c}M_{\mathrm{n}, \mathrm{BCP}} \\
(\mathrm{g} / \mathrm{mol})^{b}\end{array}$ & $Ð^{b}$ & $f_{\mathrm{PTFEA}^{c}}$ & $N^{d}$ & $\begin{array}{c}T_{\mathrm{ODT}} \\
\left({ }^{\circ} \mathrm{C}\right)^{e}\end{array}$ & Phase $^{f}$ \\
\hline 34 & 29 & 7200 & 4500 & 11700 & 1.06 & 0.27 & 153 & 150 & $\mathrm{HEX}$ \\
\hline
\end{tabular}

${ }^{a}$ Degree of polymerization (DP) and number-average molar mass of each block calculated from ${ }^{1} \mathrm{H}$ NMR end-group analysis. ${ }^{b}$ Molar mass and dispersity determined using SEC with conventional calibration in chloroform relative to PS standards. ${ }^{c}$ Volume fraction of TFEA based on reported homopolymer densities at $25{ }^{\circ} \mathrm{C}\left(0.93\right.$ and $1.403 \mathrm{~g} / \mathrm{cm}^{3}$ for PDMOA and PTFEA, respectively) and ${ }^{1} \mathrm{H}$ NMR. ${ }^{d}$ Volumetric degree of polymerization based on reported homopolymer densities and a reference volume, $v_{0}=118 \AA^{3}$. ${ }^{e}$ The order-disorder transition temperature as determined by SAXS. ${ }^{\text {P }}$ hase was determined by SAXS at $25^{\circ} \mathrm{C}$.

Table S12. Gradient profile for PTFEA- $b$-PDMOA separation (eluent: hexane/ethyl acetate).

\begin{tabular}{ccc}
\hline \%EtOAc (start) & \%EtOAc (end) & Column Volume (CV) \\
\hline 0 & 0 & 1 \\
0 & 20 & 3 \\
20 & 20 & 5 \\
\hline
\end{tabular}

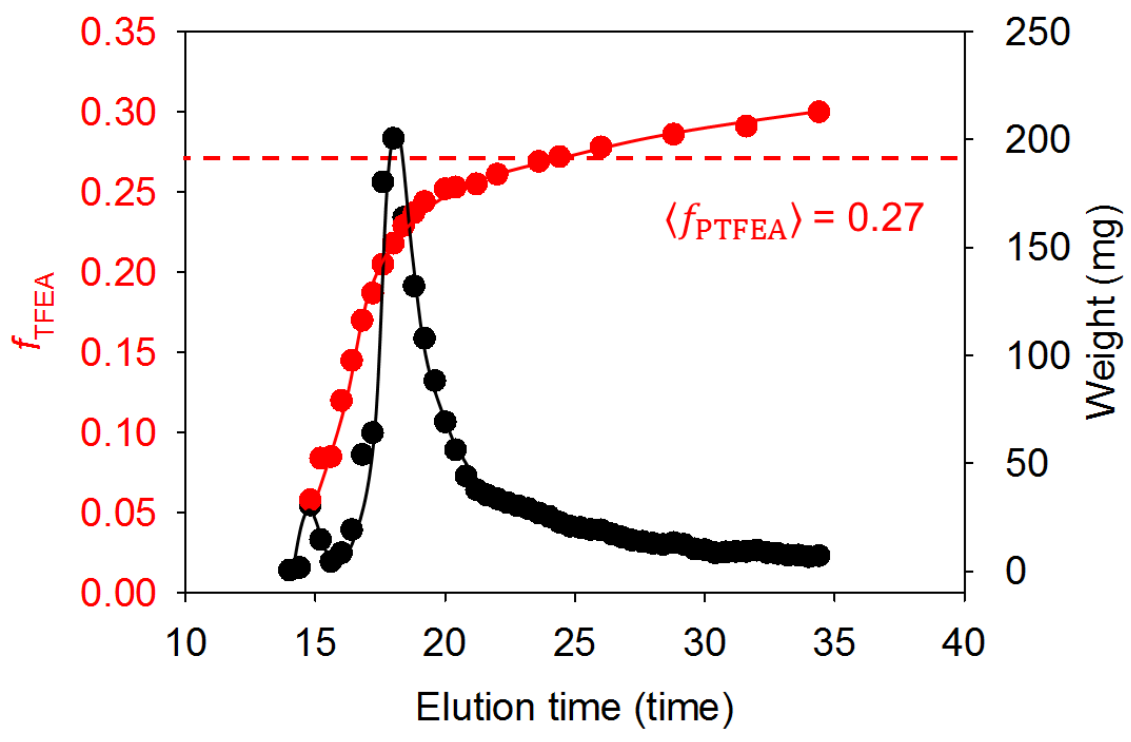

Figure S21. Chromatographic separation of PTFEA- $b$-PDMOA diblock copolymer $\left(\left\langle f_{\text {PTFEA }}\right\rangle\right.$ $=0.27$ ). The total mass recovery was $86 \%$. 


\section{Synthesis and fractionation of PTFEA- $b-\mathrm{P}( \pm) \mathrm{MnA}$ diblock copolymers}
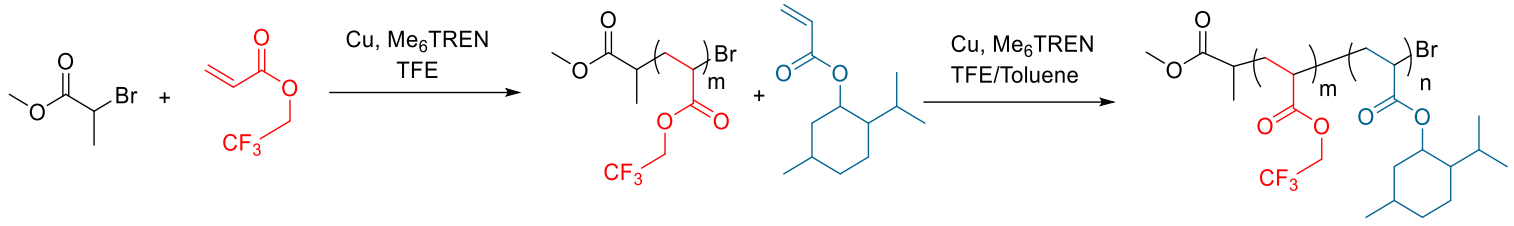

A solution of trifluoroethyl acrylate $(1.6 \mathrm{~g}, 10.4 \mathrm{mmol})$, TFE ( $2 \mathrm{~mL}), \mathrm{Me}_{6} \mathrm{TREN}(30 \mu \mathrm{L}, 0.27$ $\mathrm{mol})$, and methyl 2-bromopropionate $(73 \mu \mathrm{L}, 0.65 \mathrm{mmol})$ was prepared in a $20 \mathrm{~mL}$ scintillation vial. Oxygen was removed by degassing with argon for $10 \mathrm{~min}$. Subsequently, $2.5 \mathrm{~cm}$ of preactivated $\mathrm{Cu}(0)$ wire (20 gauge) wrapped around a Teflon-coated stirring bar was loaded under positive argon pressure, and an additional 5 min of degassing with argon was applied. To monitor the monomer conversion, drops of sample were extracted using an airtight syringe. Samples were dissolved in $\mathrm{CDCl}_{3}$ to determine the monomer conversion by ${ }^{1} \mathrm{H}$ NMR spectroscopy. The $M_{\mathrm{n}}$ and $M_{\mathrm{w}} / M_{\mathrm{n}}$ values were determined by size-exclusion chromatography with polystyrene standards. After $95 \%$ conversion was achieved for the first block at room temperature after 16 hours, a mixture of menthyl acrylate $(3.6 \mathrm{~g}, 17 \mathrm{mmol})$, TFE $(1 \mathrm{~mL})$, $\mathrm{Me}_{6}$ TREN $(30 \mu \mathrm{L}, 0.27 \mathrm{~mol})$, and toluene $(1 \mathrm{ml})$ was prepared, degassed with argon for $10 \mathrm{mins}$, and then directly injected into the previous scintillation vial. After stirring at room temperature for $24 \mathrm{~h}$, the conversion of DMOA was determined. Finally, to stop the reaction, the vial was opened to air and the polymerization mixture was dissolved in $2 \mathrm{~mL}$ of $\mathrm{CH}_{2} \mathrm{Cl}_{2}$. The resulting solution was precipitated in $50 \mathrm{~mL}$ of $\mathrm{MeOH}$ with vigorous stirring. The solvent was removed by filtration, and the final polymer was dried under vacuum. The copolymer chains that were capped with bromine atoms at the $\omega$-terminus was determined to be almost quantitative by the ratio between characteristic signals of both $\alpha$ (methyl peaks from initiator) and $\omega$ polymer terminus. 


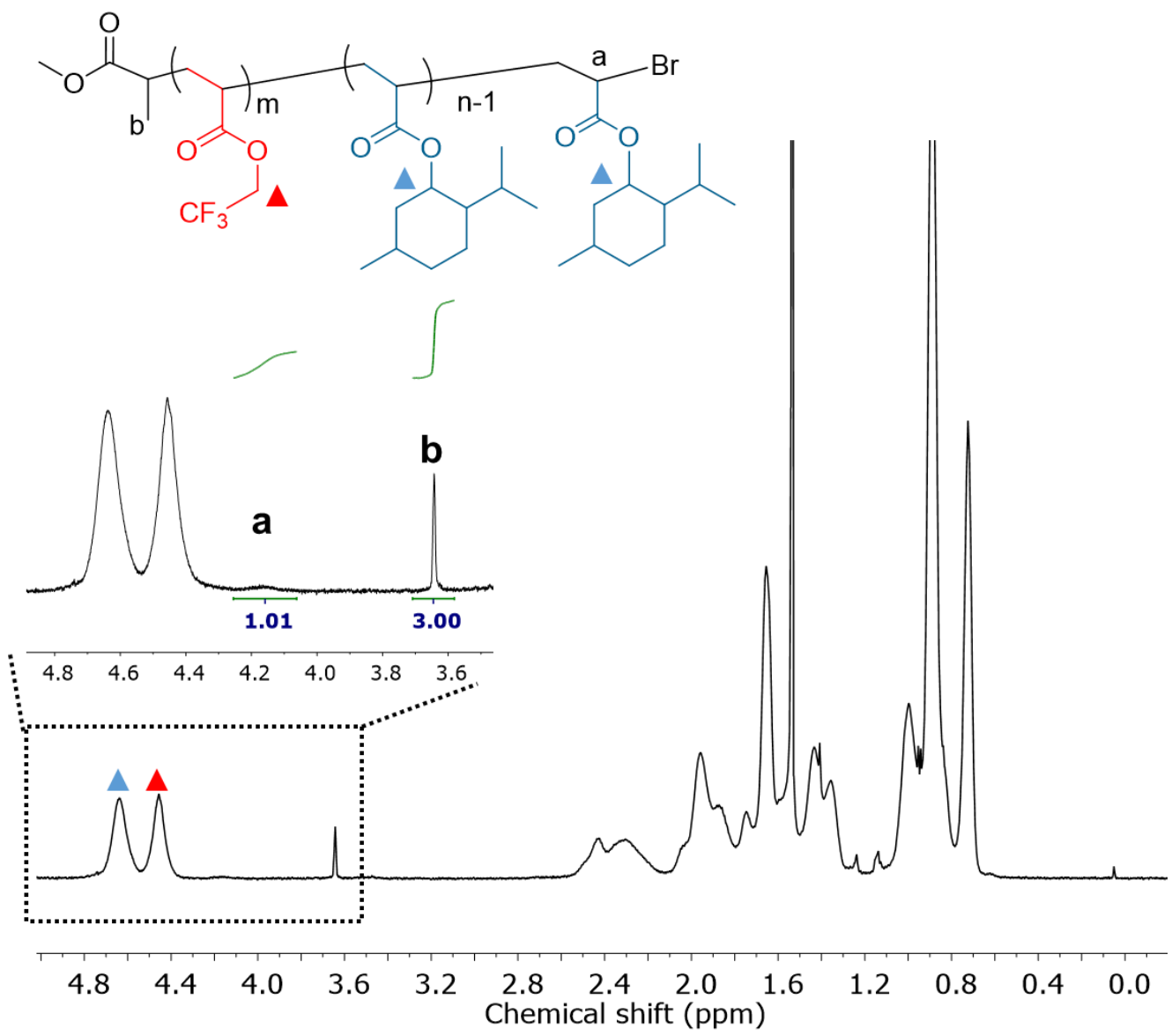

Figure S22. ${ }^{1} \mathrm{H}$ NMR spectrum of PTFEA- $b-\mathrm{P}( \pm) \mathrm{MnA}$ diblock copolymer with characteristic resonances used to calculate composition indicated by triangles. Resonances of chain end $\mathbf{a}$ and $\mathbf{b}$ were used to calculate chain end fidelity.

Table S13. Molecular characterization data for PTFEA- $b-\mathrm{P}( \pm) \mathrm{MnA}$ diblock copolymer.

\begin{tabular}{cccccccccc}
\hline$D P_{\mathrm{PMnA}^{\mathrm{a}}}$ & $D P_{\mathrm{PTFEA}{ }^{\mathrm{a}}}$ & $\begin{array}{c}M_{\mathrm{n}, \mathrm{PMnA}} \\
(\mathrm{g} / \mathrm{mol})^{a}\end{array}$ & $\begin{array}{c}M_{\mathrm{n}, \mathrm{PTFEA}} \\
(\mathrm{g} / \mathrm{mol})^{a}\end{array}$ & $\begin{array}{c}M_{\mathrm{n}, \mathrm{BCP}} \\
(\mathrm{g} / \mathrm{mol})^{b}\end{array}$ & $Ð^{b}$ & $f_{\mathrm{PTFEA}^{c}}$ & $N^{d}$ & $\begin{array}{c}T_{\mathrm{ODT}} \\
\left({ }^{\circ} \mathrm{C}\right)^{e}\end{array}$ & Phase $^{f}$ \\
\hline 50 & 23 & 11000 & 3500 & 14500 & 1.06 & 0.20 & 180 & - & DIS \\
\hline
\end{tabular}

${ }^{a}$ Degree of polymerization (DP) and number-average molar mass of each block calculated from ${ }^{1} \mathrm{H}$ NMR end-group analysis. ${ }^{b}$ Molar mass and dispersity determined using SEC with conventional calibration in chloroform relative to PS standards. ${ }^{c}$ Volume fraction of TFEA based on reported homopolymer densities at $25{ }^{\circ} \mathrm{C}\left(1.07\right.$ and $1.403 \mathrm{~g} / \mathrm{cm}^{3}$ for $\mathrm{P}( \pm) \mathrm{MnA}$ and PTFEA, respectively) and ${ }^{1} \mathrm{H}$ NMR. ${ }^{d}$ Volumetric degree of polymerization based on reported homopolymer densities and a reference volume, $v_{0}=118 \AA^{3}$. ${ }^{e}$ No order-disorder transition temperature was observed. ${ }^{f}$ Phase as determined by SAXS at $25^{\circ} \mathrm{C}$.

Table S14. Gradient profile for PTFEA- $b-\mathrm{P}( \pm) \mathrm{MnA}$ separation (eluent: hexane/ethyl acetate).

\begin{tabular}{ccc}
\hline \%EtOAc (start) & \%EtOAc (end) & Column Volume (CV) \\
\hline 0 & 0 & 1 \\
0 & 20 & 3 \\
20 & 20 & 5 \\
\hline
\end{tabular}




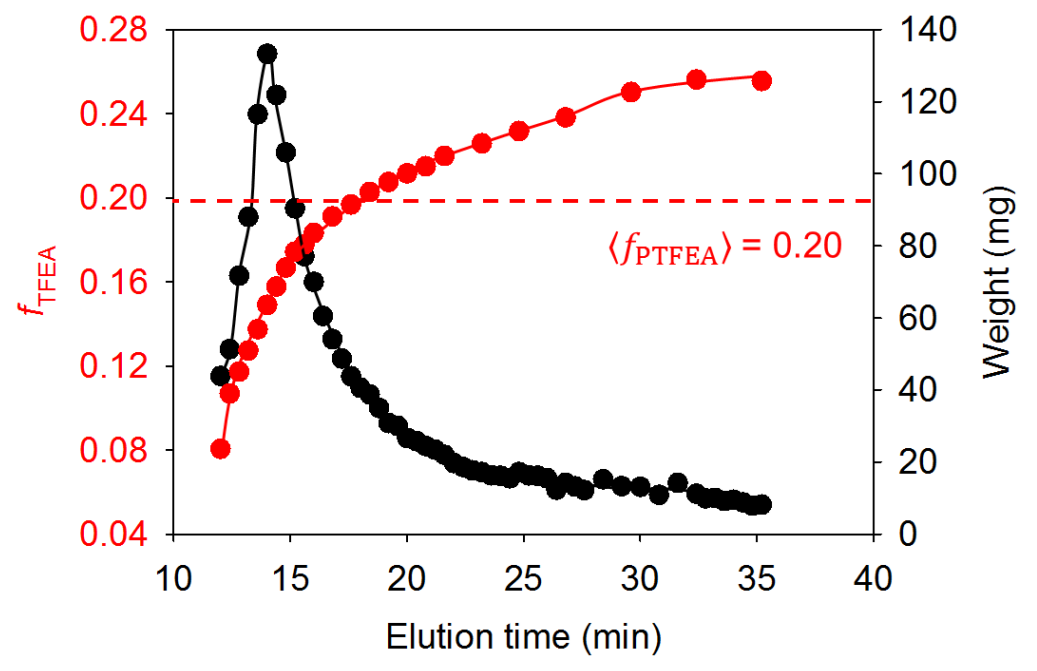

Figure S23. Chromatographic fractionation of PTFEA- $b-\mathrm{P}( \pm) \mathrm{MnA}$ diblock copolymer $\left(\left\langle f_{\text {PTFEA }}\right\rangle=0.20\right)$. The total mass recovery was $85 \%$.

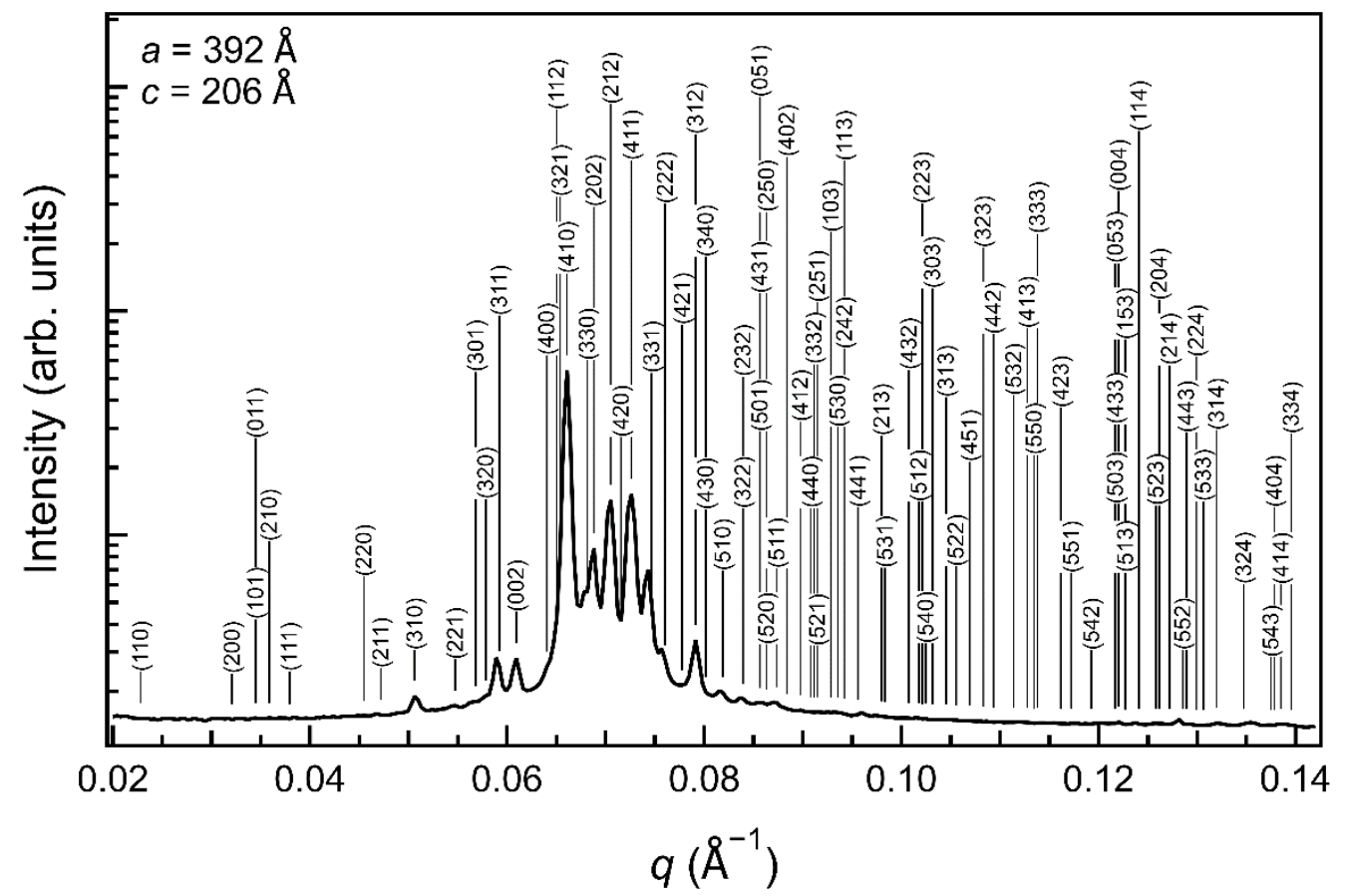

Figure S24. SAXS profile of $\sigma$ obtained with fractionated PTFEA- $b$-PDDA $\left(f_{\text {PTFEA }}=0.22\right)$. All allowed reflections for space group $\mathrm{P}_{2} / \mathrm{mnm}$ are demarcated with vertical lines. 
Table S15. Molecular characterization data for high molecular weight PTFEA- $b$-PDDA diblock copolymer.

\begin{tabular}{cccccccc}
\hline$D P_{\text {PDDA }^{\mathrm{a}}}$ & $D P$ PTFEA $^{\mathrm{a}}$ & $\begin{array}{c}M_{\mathrm{n}, \mathrm{PDDA}} \\
(\mathrm{g} / \mathrm{mol})^{a}\end{array}$ & $\begin{array}{c}M_{\mathrm{n}, \mathrm{PTFEA}} \\
(\mathrm{g} / \mathrm{mol})^{a}\end{array}$ & $\begin{array}{c}M_{\mathrm{n}, \mathrm{BCP}} \\
(\mathrm{g} / \mathrm{mol})^{b}\end{array}$ & $Ð^{b}$ & $f_{\mathrm{PTFEA}^{c}}$ & $N^{d}$ \\
\hline 100 & 71 & 24000 & 10900 & 46300 & 1.10 & 0.23 & 468 \\
\hline
\end{tabular}

${ }^{a}$ Degree of polymerization (DP) and number-average molar mass of each block calculated from ${ }^{1} \mathrm{H}$ NMR end-group analysis. ${ }^{b}$ Molar mass and dispersity determined using SEC-MALLS in THF. ${ }^{c}$ Volume fraction of PTFEA based on reported homopolymer densities at $25{ }^{\circ} \mathrm{C}(0.94$ and $1.403 \mathrm{~g} / \mathrm{cm}^{3}$ for PDDA and PTFEA, respectively) and ${ }^{1} \mathrm{H}$ NMR. ${ }^{d}$ Volumetric degree of polymerization based on reported homopolymer densities and a reference volume, $v_{0}=118 \AA^{3}$.

Table S16. Gradient profile for high molecular weight PTFEA- $b$-PDDA separation (eluent: hexane/ethyl acetate).

\begin{tabular}{ccc}
\hline \%EtOAc (start) & \%EtOAc (end) & Column Volume $(\mathrm{CV})$ \\
\hline 0 & 0 & 1 \\
0 & 33 & 3 \\
33 & 33 & 5 \\
\hline
\end{tabular}

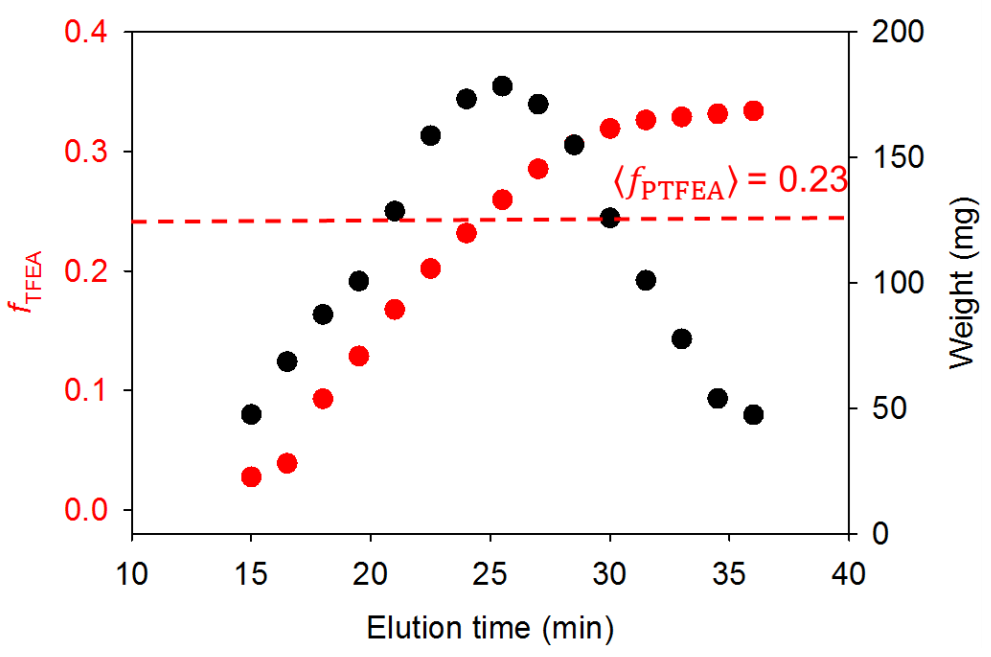

Figure S25. Chromatographic fractionation of PTFEA- $b$-PDDA diblock copolymer $\left(\left\langle M_{\mathrm{n}, \mathrm{BCP}}\right\rangle=46300 \mathrm{~g} / \mathrm{mol},\left\langle f_{\mathrm{PTFEA}}\right\rangle=0.23\right)$. Dependence of mass recovery and $f_{\text {PTFEA }}$ on elution time. The red dashed line represents $f_{\text {PTFEA }}$ before separation. The total mass recovery was $77 \%$. 


\section{REFERENCES}

1. Bates, M. W.; Lequieu, J.; Barbon, S. M.; Lewis, R. M.; Delaney, K. T.; Anastasaki, A.; Hawker, C. J.; Fredrickson, G. H.; Bates, C. M., Stability of the A15 phase in Diblock Copolymer Melts. Proc. Natl. Acad. Sci. U.S.A. 2019, 116 (27), 13194-13199.

2. Park, H.-W.; Jung, J.; Chang, T., New Characterization Methods for Block Copolymers and Their Phase Behaviors. Macromol. Res. 2009, 17 (6), 365-377.

3. Lequieu, J.; Koeper, T.; Delaney, K. T.; Fredrickson, G. H., Extreme Deflection of Phase Boundaries and Chain Bridging in $\mathrm{A}\left(\mathrm{BA}^{\prime}\right) \mathrm{n}$ Miktoarm Star Polymers. Macromolecules 2020, 53 (2), 513-522.

4. Kennemur, J. G.; Hillmyer, M. A.; Bates, F. S., Synthesis, Thermodynamics, and Dynamics of Poly(4-Tert-Butylstyrene-b-Methyl Methacrylate). Macromolecules 2012, 45 (17), 7228-7236. 